Coaxial Multistage Depressed Collector Design for High Power Gyrotrons Based on E×B Concept

\title{
Coaxial Multistage Depressed Collector Design for High Power Gyrotrons Based on E×B Concept
}

Benjamin Ell, ${ }^{1}$ loannis Gr. Pagonakis, ${ }^{1}$ Chuanren Wu, ${ }^{1}$ Manfred Thumm, ${ }^{1}$ and John Jelonnek ${ }^{1}$

Institute for Pulsed Power and Microwave Technology, Karlsruhe Institute of Technology, Karlsruhe 76131, Germany

(Dated: 6 October 2019)

The gyrotron operational efficiency is considered as a very important factor of future fusion power plants. The development of an efficient multistage depressed collector (MDC) for the annular spent electron beam is the key for a significant increase of the operational efficiency. To achieve that target, a systematic investigation of all kind of possible design approaches was conducted during the last decade at Karlsruhe Institute of Technology (KIT). A promising approach using a cylindrical hollow collector design was found. In this work, another generic design approach based on the $\mathrm{E} \times \mathrm{B}$ drift concept for the spent electron beam is presented that uses a coaxial collector design. This new generic approach offers a significant improvement in the collector efficiency. Even more, it opens the path for the design of a large variety of new MDC collectors with different characteristics, e.g. the number of stages and the wall geometry.

\section{INTRODUCTION}

Different methods are known for the heating of magnetically confined plasmas of nuclear fusion reactors, such as the neutral beam injection (NBI) and the radio frequency $(\mathrm{RF})$ heating at the cyclotron frequency of the ions (ICRH) at tens of megahertz. Electron cyclotron resonance heating $(\mathrm{EC} \mathrm{H})$ at the cyclotron frequency of the electrons and between $100 \mathrm{GHz}$ up to $300 \mathrm{GHz}$ is another method which is considered here. Gyrotrons are the only sources known to be capable of producing high frequency $\mathrm{RF}$-waves required for heating and plasma stabilization at multi-megawatt power levels. The electronic efficiency of such fusion gyrotrons, defined as the energy transferred from the electron beam to the $\mathrm{RF}$ wave is approximately $35 \%$. A total gyrotron efficiency of approximately $50 \%$ (including $10 \%$ of RF losses) is achieved by using a single-stage depressed collector (SDC) with around $60 \%$ collector efficiency ${ }^{1}$. Nevertheless, the maximum possible decelerating voltage of that kind of SDC is limited to the kinetic energy of the slowest electron at the entrance of the collector.

The question remains on how to achieve a total efficiency of higher than $60 \%$ of future gyrotrons for the DEMOnstration power plant (EU DEMO $)^{2-4}$. Operating frequencies of up to $240 \mathrm{GHz}$ and RF output powers of up to $2 \mathrm{MW}$ at continuous waves shall be achieved. Thus, considering an electronic efficiency of $35 \%$ requires a collector efficiency higher than $74 \%$. That cannot be achieved with a conventional SDC system. For that purpose, a systematic investigation of the design of multistage depressed collector (MDC) systems for fusion gyrotrons is ongoing at $\mathrm{KIT}^{5-11}$.

The design of an MDC system for high power and high frequency gyrotrons is not trivial due to the fact that the spent electron beam is confined by a relatively strong magnetic field in the order of $50 \mathrm{mT}$ in the collector region ${ }^{12}$. The sorting of the spent beam electrons according to their initial kinetic energy is essential for the increase of the collector efficiency. The therma loading on the collector wall should be in an acceptable range. The separation of the spent beam electrons of a high power gyrotron based on the $\mathrm{E} \times \mathrm{B}$ drift concept was proposed in $2008^{5}$ and is considered as the most promising method ${ }^{12-14}$. Since then, three different types of MDC designs have been suggested for annular gyrotron electron beams based on the $\mathrm{E} \times \mathrm{B}$ drift. The first type is based on the transformation of the annular beam to a sheet beam ${ }^{6,9}$, the second type consists of the application of an azimuthal magnetic field on the annular beam ${ }^{15,16}$ and the third one is based on utilizing an azimuthal electric field ${ }^{5,10,11}$

In Ref. ${ }^{5}$, a design approach for a cylindrical coaxial collector was presented for the demonstration of the $\mathrm{E} \times \mathrm{B}$ drift concept. In that work, an infinite number of stages was considered due to the fact that no full three-dimensional simulation tool was available at that time. The main goal of the present work is to design realistic MDC systems based on that idea with a finite number of electrodes for a typical spent electron beam of a high power gyrotron. It is also afforded to demonstrate a plurality of designs of different MDC systems that could be manufactured based on that approach.

Several theoretical issues related to the design approach studied in this work are presented in Sec. II. The numerical model used for the simulations and the investigation of several design parameters is discussed in Sec. III. The influence of the space charge and the secondary electrons on the MDC operation is presented in Sec. IV, while the power loading on the collector wall is discussed in Sec. V.

\section{THEORY}

Two schematic views of a gyrotron with an SDC and a two-stage MDC are shown in Fig. 1. In the SDC case, two power supplies are used for the definition of the cathode and body potentials, while the collector is usually grounded ${ }^{17}$. On the other hand, the potentials of 


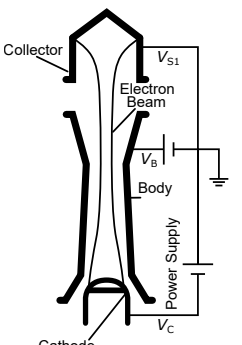

(a) SDC

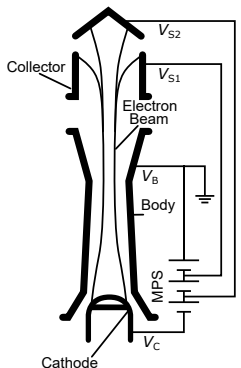

(b) MDC
FIG. 1. Schematic view of an SDC (a) and an MDC (b) with the corresponding power supplies.

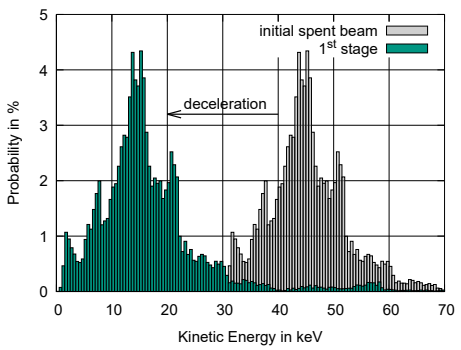

(a) SDC

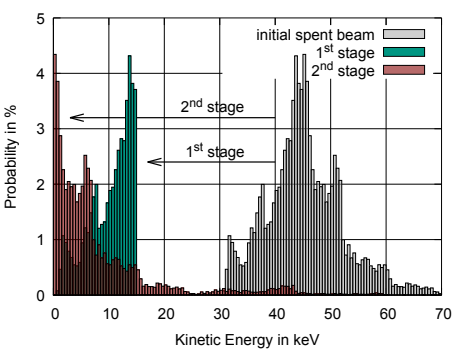

(b) MDC

FIG. 2. Energy distribution of the spent electron beam of a $1 \mathrm{MW}$ gyrotron with an SDC (a) and a two-stage MDC (b) before and after deceleration.

the cathode $\left(V_{\mathrm{C}}\right)$, the first $\left(V_{\mathrm{S} 1}\right)$ and second $\left(V_{\mathrm{S} 2}\right)$ stage of the MDC are provided by a modular power supply $(\mathrm{MPS})^{18}$.

The energy distribution before and after deceleration of the spent beam electrons for the SDC and the two-stage MDC are shown in Fig. 2. For the SDC, all spent beam electrons are decelerated by the same potential difference, which is limited by the energy of the slowest electron in order to ensure that no electron is reflected back to the cavity. On the other hand,

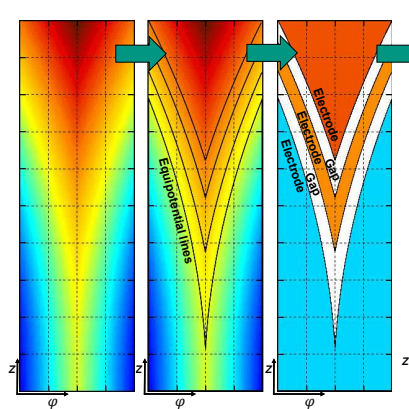

(a) (b)

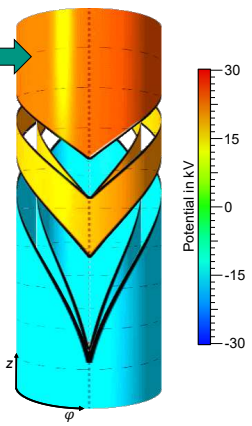

(d)
FIG. 3. Electric potentials at the boundaries of the coaxial cylindrical MDC with a smoothly varying electric potential on an unrolled cylindrical surface (a), four equipotential lines (b), discrete electrodes with three different potentials (c) and a three-dimensional representation (d).

in the MDC scheme, the slow electrons are decelerated by $30 \mathrm{kV}$, while the faster electrons are decelerated by an additional $15 \mathrm{kV}$ in this example. Therefore, the remaining energy of the electron beam is further reduced, while the collector efficiency is additionally increased.

Two concepts have been proposed for the efficient sorting of the spent beam electrons according to their kinetic energy in gyrotrons. The first one is the symmetric concept which involves special demagnetization processes at the collector ${ }^{8,19,20}$, while the second one is based on the $\mathrm{E} \times \mathrm{B}$ drift approach ${ }^{5}$. This second approach has some advantages, such as a small influence of secondary electrons, insensitivities to the energy distribution, stray magnetic field and misalignments, as it is extensively discussed in Ref. ${ }^{12}$.

\section{DESIGN STUDIES}

For the demonstration of the $\mathrm{E} \times \mathrm{B}$ drift concept in Ref. $^{5}$ a theoretical MDC design was proposed with a collector efficiency in the order of $91 \%$ for the spent electron beam of the $2 \mathrm{MW}$ coaxial cavity gyrotron operating at ITER frequency ${ }^{21,22}$. The implementation of the $\mathrm{E} \times \mathrm{B}$ drift concept on the annular gyrotron electron beam was achieved with the application of an azimuthal component of the electric field $E_{\varphi}$. Due to Faraday's law, it is not possible to have the same direction for the azimuthal component of the electric field for all azimuthal angles. Therefore, a positive azimuthal electric field was applied to the half part of the annular beam, between the azimuthal angles 0 and $\pi$, while a negative azimuthal electric field was applied to the other half. Therefore, half of the electrons are drifting outwards to an outer cylindrical surface and the other half inwards to an inner cylindrical surface. 


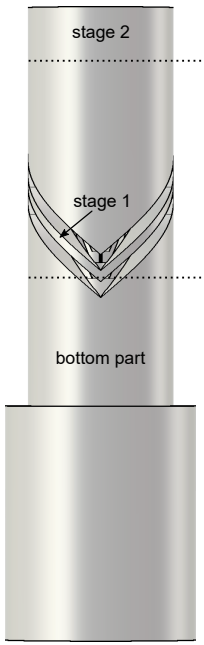

(a) CST

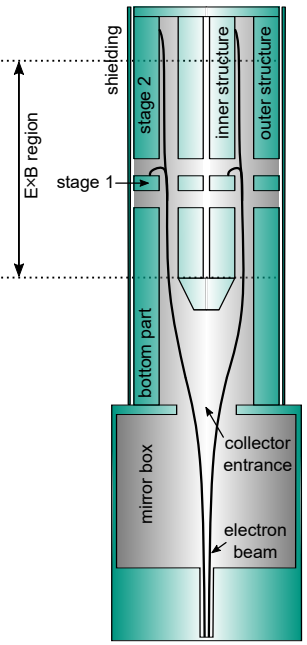

(b) vertical cross-section
FIG. 4. Basic shape of the coaxial two-stage depressed collector.

The required electric field was defined by an infinite number of electrodes, which in the simulation were defined as a Dirichlet type of boundary condition of the electrical potential to the inner and the outer cylindrical surface of the coaxial collector. The value of the potential on these two surfaces was defined as functions of the axial position $z$ and the azimuthal angle $\varphi$, as shown in Fig. 3(a). The steps, which were followed to define the MDC geometry with a small number of electrodes from the theoretical design with an infinite number of electrodes, are shown in Fig. 3(b-d). First, four equipotential lines separating the boundary condition of the electric potential into five segments. Then, two segments in between are removed and constant potentials are defined on the remaining three segments. Finally, the potentials are mapped to the inner and outer collector surface.

The replacement of the smooth varied boundary condition with a small number of electrodes has a significant influence on the electric field. Therefore, the smooth variation of the electric field along the electron trajectories is replaced by the stronger electric field in the gap between neighboring electrodes. However, as discussed in Ref. ${ }^{6}$, the electron drift due to $\mathrm{E} \times \mathrm{B}$ depends only on the potential and not how the electric field is varied. The design presented in this article with a discrete and finite number of electrodes should also work, even though the original ideal required smoothly varying electric potentials.

The three dimensional commercial simulation tool CST was used for the design and the optimization of the MDC. The geometry of the complex shape of

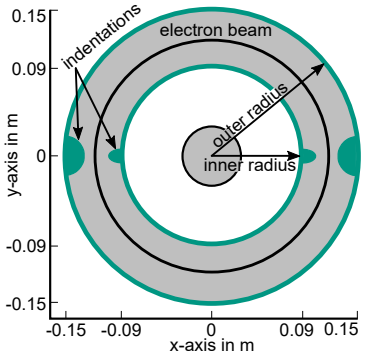

FIG. 5. Horizontal cross-section of the coaxial two-stage depressed collector.

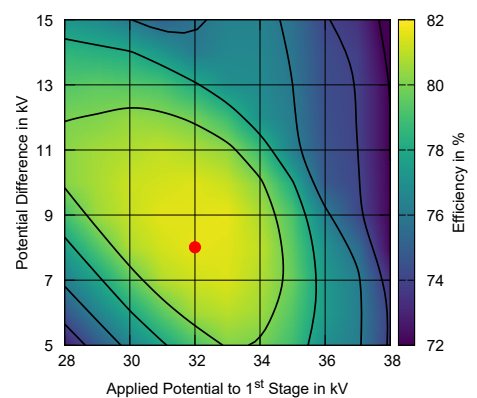

FIG. 6. Efficiency versus the depression potentials.

the collector electrodes is defined by a combination of Boolean operations on cylindrical, conical and hexahedral structures. A graphical representation of the two-stage depressed collector as it is created in CST is shown in Fig. 4(a), whereas a vertical cross-section of the coaxial collector is shown in Fig. 4(b). As shown in Fig. 5 , indentations were applied on the inner and outer walls at the two azimuthal angles where the helices discontinue to minimize the probability of reflected electrons similar to Ref. ${ }^{5}$. In order to achieve a realistic simulation of the electron beam, the gyrotron mirror vessel and the launcher were also modeled.

Initially, the material used in CST for the definition of the electrodes was a perfect electrical conductor (PEC). The spent electron beam was imported at the launcher entrance via the particle interface. A number of 100,000 electrons emulated the spent electron beam. The initial kinetic energies and positions of these electrons were calculated with the in-house software Ariadne based on gyrotron cavity interaction ${ }^{23}$. The static magnetic field in the simulation region was also calculated by the Ariadne code and imported to $\mathrm{CST}^{24}$.

The influence of the most important operating and geometrical parameters on the operation of the MDC system was investigated for the two-stage depressed collector. The electrode potentials are optimized for the spent electron beam to accomplish the desired behavior 


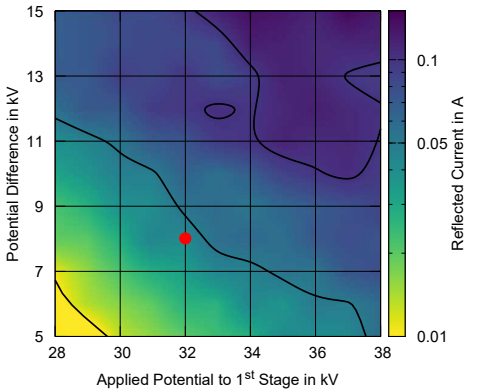

FIG. 7. Reflected current versus the depression potentials.

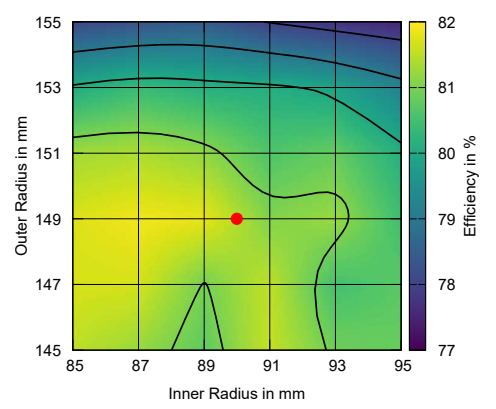

FIG. 8. Efficiency versus the inner and outer collector radii.

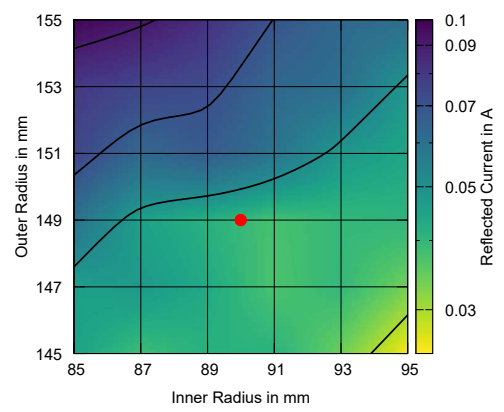

FIG. 9. Reflected current versus the inner and outer collector radii.

of the collector. The collector efficiency of a two-stage collector versus the depression potentials applied to the stages is shown in Fig. 6. The efficiency of the collector is significantly influenced by the applied potential on the electrodes. An important parameter in which a special attention should be paid is the reflected current. Actually, a number of electrons could theoretically return back to the cavity influencing the interaction with the RF field. This current should be kept as low as possible. As shown in Fig. 7, the reflected current is in the range of

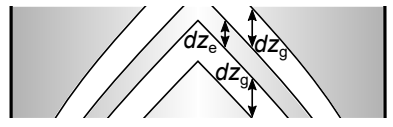

FIG. 10. Distance between the stages $d z_{\mathrm{g}}$ and $2^{\text {nd }}$ electrode thickness $d z_{\mathrm{e}}$.

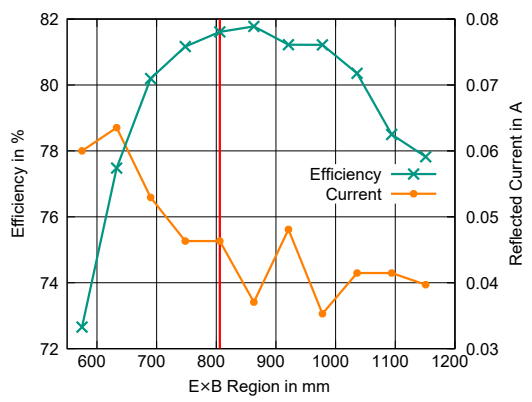

FIG. 11. Efficiency and reflected current versus the length of the $\mathrm{E} \times \mathrm{B}$ region $l_{\mathrm{E} \times \mathrm{B}}$.

$50 \mathrm{~mA}$ for the area where the efficiency has the maximum value. The nominal potentials are set to $32 \mathrm{kV}$ and $40 \mathrm{kV}$ for the first and second stage, respectively.

The radii of the inner and outer wall of the collector are also essential for an efficient collection of the spent beam electrons. A large distance between the collector wall and the electron beam at the entrance causes the collection of the electrons at a point where the kinetic energy is already increasing again due to reflections. A small distance, on the other hand, would cause a collection of the beam before the kinetic energy is minimized. The collector efficiency versus the inner and outer wall radii is shown in Fig. 8, whereas the reflected current is shown in Fig. 9. The nominal radii for the inside and outside of the collector are set to $90 \mathrm{~mm}$ and $149 \mathrm{~mm}$.

Two additional geometrical parameters of the MDC design are the distance $d z_{\mathrm{g}}$ between the stages and the thickness $d z_{\mathrm{e}}$ of the first stage as shown in Fig. 10. The collector efficiency and the reflected current are nearly constant versus the thickness of the first stage. The nominal stage thickness was set to $35 \mathrm{~mm}$ for a reduced weight and size of the MDC. The collector efficiency and the reflected current are decreasing with increasing distance between the stages. The nominal distance between the stages of the collector was set to $50 \mathrm{~mm}$. A larger distance between the stages would cause an unwanted increase of the reflected current and a minor decrease of the efficiency. The advantage of a small distance is therefore mainly a reduced reflected current. On the other hand, the small values of distance have impact on the maximum electric field, which reaches potentially a critical range at the inner structure.

The radial drift distance of the electrons is directly proportional to the slope of the helix and therefore the 


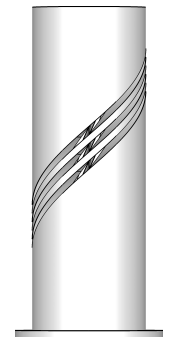

(a) thre

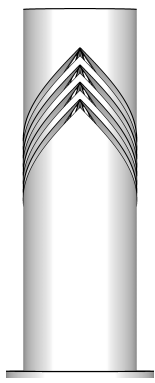

(b) four
FIG. 12. Three- and four-stage depressed collectors.

TABLE I. Results for a Different Number of Collector Stages Collector stages Theoretical optimal collector efficiency in \% Collector efficiency in \%

Reflected current in $\mathrm{mA}$

\begin{tabular}{c|ccc}
2 & 3 & 4 \\
\hline 83.5 & 87.3 & 90.7 \\
81.9 & 83.2 & 87.4 \\
45.4 & 41.5 & 38.8
\end{tabular}

length of the $\mathrm{E} \times \mathrm{B}$ region $l_{\mathrm{E} \times \mathrm{B}}$. The collector efficiency and reflected current versus $l_{\mathrm{E} \times \mathrm{B}}$ are shown in Fig. 11 . This result is only valid for the given definition of the other parameters and the optimal $l_{\mathrm{E} \times \mathrm{B}}$ would be different if one parameter is varied. The efficiency is decreasing for either small or large $l_{\mathrm{E} \times \mathrm{B}}$. The electron drift is not high enough in case of a small $l_{\mathrm{E} \times \mathrm{B}}$ for an efficient electron separation and collection on the optimal collector stage.

The collector efficiency is increasing with the number of depressed stages, which in turn increases the complexity of the mechanical construction. An additional layer of insulation (a helical gap) and high voltage and cooling feeds are necessary for every increment in the number of depressed stages. The geometries of MDCs with three- and four-stages are shown in Fig. 12, while the efficiencies achieved in simulations are listed in Tab. I. The efficiency of the MDC is increasing with the number of stages as expected with values close to the theoretical optimal efficiencies. On the other hand, the reflected current is not significantly influenced by the number of stages.

The size of the collector can be significantly decreased by a folded helical gap as was also proposed in Ref. ${ }^{11}$. The regions of an inward and outward drift are split into more regions with a smaller azimuthal section for each fragment. The design with a one-time folded spiral is shown in Fig. 13(a), while the design with a two times folded spiral is shown in Fig. 13(b). A collector with a single folded helix is defined to have twice the number of inward and outward drift regions as a collector with an unfolded helix. This number is again doubled for a collector with two-times folded helix. The initial axial

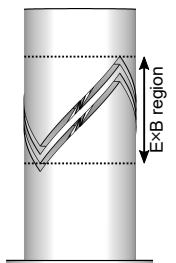

(a) one fold

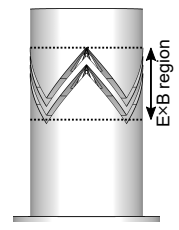

(b) two folds
FIG. 13. Two-stage depressed collectors with folded helical structure.

TABLE II. Axial dimensions of the different types

\begin{tabular}{l|ccc} 
No. of helix folds & 0 & 1 & 2 \\
\hline Length of $\mathrm{E} \times \mathrm{B}$ region in $\mathrm{mm}$ & 805 & 464 & 286
\end{tabular}

position of the helical gap is given by the magnetic field constraints and the desired beam radius. The length of the $\mathrm{E} \times \mathrm{B}$ region is shown in Tab. II. The achieved performance of the designs with folded helical structure is similar to the unfolded collector.

It should be mentioned that a variety of designs could be made by variations of the proposed approach. In particular, there is the possibility to place an insulator between the gyrotron mirror vessel and the collector to reduce the number of helical gaps by one. Another option is to replace the cylindrical shape of the electrodes with a conical shape. In this way, the additional collector coil system, necessary for the generation of the required magnetic field, is simplified.

\section{SPACE CHARGE AND SECONDARY ELECTRONS}

In the simulation results presented earlier, the space charge of the electron beam was not taken into account. To study the influence of the space charge on the MDC operation, a self-consistent approach is used. Several iterations are required to reach the steady state conditions. Each iteration is finished after all electrons are collected (trajectory approach). In case of verifications using the PIC method, the simulation stops when a stationary state is reached. The influence of space charge on the collector efficiency is approximately one percentage point and the reflected current is increased to $71.9 \mathrm{~mA}$ which is still negligible.

Another important factor, which could influence the operation of the MDC are the secondary electrons emitted from the electrodes after their bombardment with the spent beam electrons. In the simulation model, the collector material is set to copper including the Furman model for the emission of secondary electrons ${ }^{25}$.

An important advantage of the $\mathrm{E} \times \mathrm{B}$ drift concept is that the secondary electrons which are also influenced by the $\mathrm{E} \times \mathrm{B}$ drift, move deeper into the gap between the 
neighboring electrodes ${ }^{5}$. Therefore, the probability to move backwards to the cavity influencing the electronic efficiency, as it can be the case for the conventional single stage depressed collector, is low. Indeed, the reflected current was always negligible in all simulations performed considering secondary electrons. There are secondary electrons (mainly of the first generation) which achieve to reach the neighboring electrode with a less negative potential influencing in that way the efficiency of the collector. Due to that fact, a drop in the collector efficiency from $81.9 \%$ to $76.7 \%$ for the two-stage collector and from $87.4 \%$ to $81.2 \%$ for the four-stage collector was calculated, considering only the first generation of secondary electrons. The influence of the second generation of secondary electrons was also studied only for the two-stage collector and an additional efficiency reduction of less than one percent was observed. It should be noted that the simulation with a higher generation of secondary electrons of the three-dimensional geometry is not trivial. It is a very time consuming process due to the fact that very slow secondary electrons are generated which require an extremely long time to hit the electrodes. The effect of secondary electrons of a higher generation than one is not expected to be significant due to the feature that they cannot escape from the region between the electrodes.

After time consuming simulations it was observed that the efficiency can be slightly improved by optimizing the geometrical and operational parameters considering the secondary electrons. In particular, it was primarily observed that an increase of the distance between the electrodes can be beneficial to suppress the influence of secondary electrons.

The behavior of secondary electrons have also been checked previously in a similar structure ${ }^{10}$. There, both trajectory tracing and particle-in-cell was applied where more than one generation of secondary electrons were considered. The results from both methods were in agreement and the expectation that the secondary electrons might not be problematic at the collector was also shown in those simulations. A comprehensive study has to be conducted in order to deeply understand the behavior of secondary electrons in MDCs to avoid the reduction of the collector efficiency.

\section{POWER LOADING}

The power loading on the collector wall is an essential issue for the design of a functional collector. The collector could be damaged if the power loading on the collector wall exceeds the technically acceptable limit or if the collector is not cooled appropriately. Several simulations are performed to estimate the loading on the electrodes for a few designs. In these simulations, space charge and secondary electron emission were ignored for the limitation of CST.

The power loading on the collector wall of a two-stage

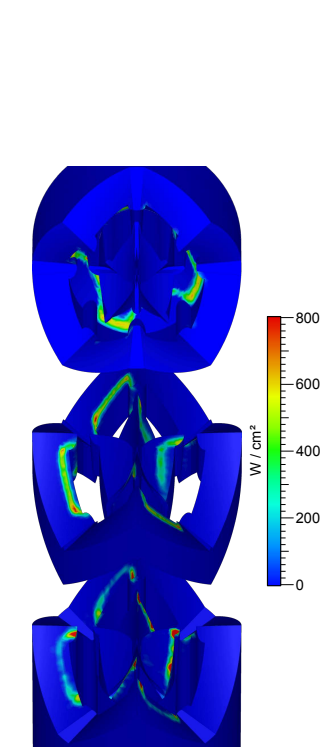

(a) two-stage

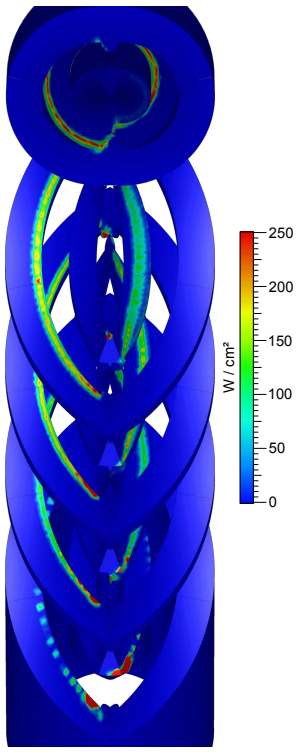

(b) four-stage
FIG. 14. Power loading of a two-stage and a four-stage depressed collector as shown in Fig. 13b and Fig. 12b in exploded view.

TABLE III. Power loading distribution with depression potentials of $33 \mathrm{kV}$ and $43 \mathrm{kV}$ for the two-stage and $31 \mathrm{kV}$, $38 \mathrm{kV}, 43 \mathrm{kV}$ and $52 \mathrm{kV}$ for the four-stage collector.

\begin{tabular}{l|cc} 
Collector stages & 2 & 4 \\
\hline GND power in $\mathrm{kW}$ & 34.7 & 45.6 \\
$1^{\text {st }}$ stage in $\mathrm{kW}$ & 64.7 & 45.4 \\
$2^{\text {nd }}$ stage in $\mathrm{kW}$ & 268 & 44.0 \\
$3^{\text {rd }}$ stage in $\mathrm{kW}$ & - & 48.9 \\
$4^{\text {th }}$ stage in $\mathrm{kW}$ & - & 71.7
\end{tabular}

depressed collector with a two times folded helix and a four-stage collector with an unfolded helix are shown in Fig. 14. The scale of the power density is adjusted to each result. It can be seen that the power is distributed to the different stages of the collector in a mostly uniform way. However, some small areas with higher loading are located in close vicinity to the helix discontinuities. The loading on these small areas could be reduced with further optimization of the shape of the indentations. The power loading density of the four-stage collector is significantly reduced in comparison to the two-stage collector as it is presented in Tab. III. It is remarkable that the power loading on the electrodes of the MDC with four stages is uniformly distributed and their values are less than $75 \mathrm{~kW}$ per stage. The distribution of power to the different electrodes is adjustable with the depression 
potentials.

\section{CONCLUSION}

A variety of MDC systems for a typical spent electron beam energy distribution of a high power gyrotron were designed and optimized. All designs are based on the $\mathrm{E} \times \mathrm{B}$ drift concept for the separation of the spent beam electron trajectories according to their initial kinetic energy. High collector efficiencies were numerically achieved with low reflected current. The possibility of a significant decrease in size based on the folded helical structure was demonstrated without significantly influencing the MDC performance. The power loadings of two sample collectors were also studied. The power loading could be significantly reduced for an MDC system with four stages. The major advantage of using more stages is the better power distribution onto more electrodes, which could be vital in the case of the design of an MDC system for a $2 \mathrm{MW}$ continuous wave gyrotron. Depending on the configuration, the secondary electrons could lead to a few percent drop of the efficiency. A more comprehensive study should be performed in the future in order to better understand how the secondary electrons influence the MDC operation based on the $\mathrm{E} \times \mathrm{B}$ concept and to optimize the design in order to avoid that efficiency reduction.

The design of a mechanical prototype is not trivial. Many technical issues, such as the insulation and the cooling of the electrodes, the connection of the electrodes with the power supply, etc., should be addressed. These important issues will be the main subject of a future work.

\section{ACKNOWLEDGMENT}

This work has been carried out within the framework of the EUROfusion Consortium and has received funding from the Euratom research and training programme 2014-2018 and 2019-2020 under grant agreement No 633053. The views and opinions expressed herein do not necessarily reflect those of the European Commission. The authors would like to warmly thank Dr. E. Borie for her contribution to the text quality of the manuscript.

\section{REFERENCES}

${ }^{1}$ T. Omori, M. Henderson, F. Albajar, S. Alberti, U. Baruah, T. Bigelow, B. Beckett, R. Bertizzolo, T. Bonicelli, A. Bruschi, J. Caughman, R. Chavan, S. Cirant, A. Collazos, D. Cox, C. Darbos, M. de Baar, G. Denisov, D. Farina, F. Gandini, T. Gassmann, T. Goodman, R. Heidinger, J. Hogge, S. Illy, O. Jean, J. Jin, K. Kajiwara, W. Kasparek, A. Kasugai, S. Kern, N. Kobayashi, H. Kumric, J. Landis, A. Moro, C. Nazare, Y. Oda, I. Gr. Pagonakis, B. Piosczyk, P. Platania, B. Plaum, E. Poli,

L. Porte, D. Purohit, G. Ramponi, S. Rao, D. Rasmussen,
D. Ronden, T. Rzesnicki, G. Saibene, K. Sakamoto, F. Sanchez, T. Scherer, M. Shapiro, C. Sozzi, P. Spaeh, D. Strauss, O. Sauter, K. Takahashi, R. Temkin, M. Thumm, M. Tran, V. Udintsev, and H. Zohm, "Overview of the ITER EC H\&CD system and its capabilities," Fusion Engineering and Design 86, 951 - 954 " Fus 26 th Symposium of Fusion Technology (SOFT-26)

2 J. Jelonnek, G. Aiello, S. Alberti, K. Avramidis, F. Braunmueller, A. Bruschi, J. Chelis, J. Franck, T. Franke, G. Gantenbein, S. Garavaglia, G. Granucci, G. Grossetti, S. Illy, Z. C. Ioannidis, J. Jin, P. Kalaria, G. P. Latsas, I. Gr. Pagonakis, T. Rzesnicki, S. Ruess, T. Scherer, M. Schmid, D. Strauss, C. Wu, I. Tigelis, D. Thum EUROfusion," Fusion Engineering and Design 123, 241-246 (2017), proceedings of the 29th Symposium on Fusion Technology (SOFT-29) Prague, Czech Republic, September 5-9, 2016.

${ }^{3}$ M. Thumm, J. Franck, P. C. Kalaria, K. A. Avramidis, G. Gantenbein, S. Illy, I. Gr. Pagonakis, C. Wu, J. Zhang, and J. Jelonnek, "Towards a $0.24-\mathrm{THz}, 1-$ to $2-\mathrm{MW}$-class gyrotron for DEMO," in 5th Shenzhen International Conference on Advanced Science and Technology (SICAST 2015), Shenzhen, China, August 18-22 (2015).

${ }^{4}$ J. Franck, Systematic Study of Key Components for a CoaxialCavity Gyrotron for DEMO, Ph.D. thesis, Karlsruhe Institute of Technology (KIT) (2017).

${ }^{5}$ I. Gr. Pagonakis, J.-P. Hogge, S. Alberti, K. A. Avramides, and J. L. Vomvoridis, "A New Concept for the Collection of an Electron Beam Configured by an Externally Applied Axial 480 (2008)

${ }^{6}$ I. Gr. Pagonakis, C. Wu, S. Illy, and J. Jelonnek, "Multistage depressed collector conceptual design for thin magnetically confined electron beams," Physics of Plasmas 23, 043114 (2016).

G. Iing, B. Piosc multistage depressed collector for gyrotrons," IEEE Transactions on Plasma Science 28, 606-613 (2000).

${ }^{8}$ C. Wu, I. Gr. Pagonakis, S. Illy, M. Thumm, G. Gantenbein, and J. Jelonnek, "Preliminary studies on Multistage Depressed Collectors for fusion gyrotrons," in 2016 German Microwave Conference (GeMiC) (2016) pp. 365-368.

${ }^{9}$ C. Wu, I. Gr. Pagonakis, G. Gantenbein, S. Illy, M. Thumm, and J. Jelonnek, "Conceptual designs of $\mathrm{E} \times \mathrm{B}$ multistage depressed collectors for gyrotrons," Physics of Plasmas 24 (2017).

${ }^{10}$ C. Wu, I. Gr. Pagonakis, K. A. Avramidis, G. Gantenbein, S. Illy, M. Thumm, and J. Jelonnek, "Gyrotron multistage depressed collector based on $\mathrm{E} \times \mathrm{B}$ drift concept using azimuthal electric field. I. Basic design," Physics of Plasmas 25, 033108 (2018).

${ }^{11} \mathrm{C}$. Wu, I. Gr. Pagonakis, D. Albert, K. A. Avramidis, G. Gantenbein, S. Illy, M. Thumm, and J. Jelonnek, "Gyrotron multistage depressed collector based on $\mathrm{E} \times \mathrm{B}$ drift concept using azimuthal electric field. II: Upgraded designs," Physics of Plasmas 26, 013108 (2019), https://doi.org/10.1063/1.5078861.

${ }^{12}$ C. Wu, I. Gr. Pagonakis, S. Illy, G. Gantenbein, M. Thumm, and J. Jelonnek, "Comparison between controlled non-adiabatic and $\mathrm{E} \times \mathrm{B}$ concepts for gyrotron multistage depressed collectors," EPJ Web of Conferences 149, 04005 (2017).

${ }^{13}$ V. Manuilov, M. Morozkin, O. Luksha, and M. Glyavin, "Gyrotron collector systems: Types and capabilities," Infrared Physics \& Technology 91, 46-54 (2018)

${ }^{14} \mathrm{M}$. Glyavin, V. Manuilov, and M. Morozkin, "Two-stage Energy Recovery System for DEMO Gyrotron," in $201843 \mathrm{rd}$ International Conference on Infrared, Millimeter, and Terahertz Waves (IRMMW-THz) (2018) pp. 1-2.

${ }^{15} \mathrm{O}$. I. Louksha and P. A. Trofimov, "A Method of Electron Separation for Multistep Recuperation Systems in Gyrotrons," Technical Physics Letters 41, 884-886 (2015).

${ }^{16}$ O. I. Louksha and P. A. Trofimov, "A multistage depressed collector system for gyrotrons," in 2017 Eighteenth International Vacuum Electronics Conference (IVEC) (2017) pp. 1-2. 
${ }^{17} \mathrm{M}$. Thumm, "Progress in gyrotron development," Fusion Engineering and Design 66-68, 69-90 (2003), 22nd Symposium on Fusion Technology.

${ }^{18}$ M. Schmid, J. Franck, P. Kalaria, K. Avramidis, G. Gantenbein, S. Illy, J. Jelonnek, I. Gr. Pagonakis, T. Rzesnicki, and M. Thumm, "Gyrotron development at KIT: FULGOR test facility and gyrotron concepts for DEMO," Fusion Engineering facility and gyrotron concepts for DEMO," Fusion Engineering
and Design 96-97, 589-592 (2015), proceedings of the 28th Symposium On Fusion Technology (SOFT-28).

${ }^{19}$ A. Singh, S. Rajapatirana, Y. Men, V. L. Granatstein, R. L. Ives, and A. J. Antolak, "Design of a multistage depressed collector system for 1-MW CW gyrotrons. I. Trajectory control of primary and secondary electrons in a two-stage depressed collector," IEEE Transactions on Plasma Science 27, 490-502 (1999).

${ }^{20}$ M. Y. Glyavin, M. V. Morozkin, and M. I. Petelin, "Separation of energy fractions of an electron beam by a localized nonuniformity of magnetic field in the collector region of gyrodevices," Radiophysics and Quantum Electronics 49, 811-815 (2006).

${ }^{21}$ J. Hogge, F. Albajar, S. Alberti, P. Benin, T. Bonicelli, S. Cirant, D. Fasel, T. Goodman, S. Illy, S. Jawla, C. Lievin, I. Pagonakis, A. Perez, B. Piosczyk, L. Porte, T. Rzesnicki, M. Thumm, and M. Q. Tran, "The European $2 \mathrm{MW}, 170 \mathrm{GHz}$ coaxial cavity gyrotron for ITER," in Joint 32nd International Conference on Infrared and Millimetre Waves and 15th International Conference on TeraHertz Electronics, Cardiff, UK, Sept. 2nd - 7th (2007) pp. 38-40.

${ }^{22}$ S. Kern, J. P. Hogge, S. Alberti, K. Avramides, G. Gantenbein, S. Illy, J. Jelonnek, J. Jin, F. Li, I. Gr. Pagonakis, B. Piosczyk, T. Rzesnicki, M. K. Thumm, I. Tigelis, M. Q. Tran, and EU Home Team at EGYC, "Experimental results and recent developments on the EU $2 \mathrm{MW} 170 \mathrm{GHz}$ coaxial cavity gyrotron for ITER," The European physical journal / Web of Conferences 32, Art.Nr. 04009 (2012).

${ }^{23} \mathrm{~J}$. Gr Pagonakis and J. L. Vomvoridis, "Evolution of an electron beam with azimuthal density nonuniformity in a cylindrical beam tunnel," IEEE Transactions on Plasma Science 32, 890-898 (2004).

${ }^{24}$ I. Gr. Pagonakis, K. A. Avramidis, G. Gantenbein, T. Rzesnicki, A. Samartsev, and J. Jelonnek, "Magnetic field profile analysis for gyrotron experimental investigation," Physics of Plasmas 24, 033102 (2017), https://doi.org/10.1063/1.4977460.

${ }^{25}$ M. A. Furman and M. T. Pivi, "Probabilistic model for the simulation of secondary electron emission," Physical Review Special Topics Accelerators and Beams 5, 124404 (2002). 


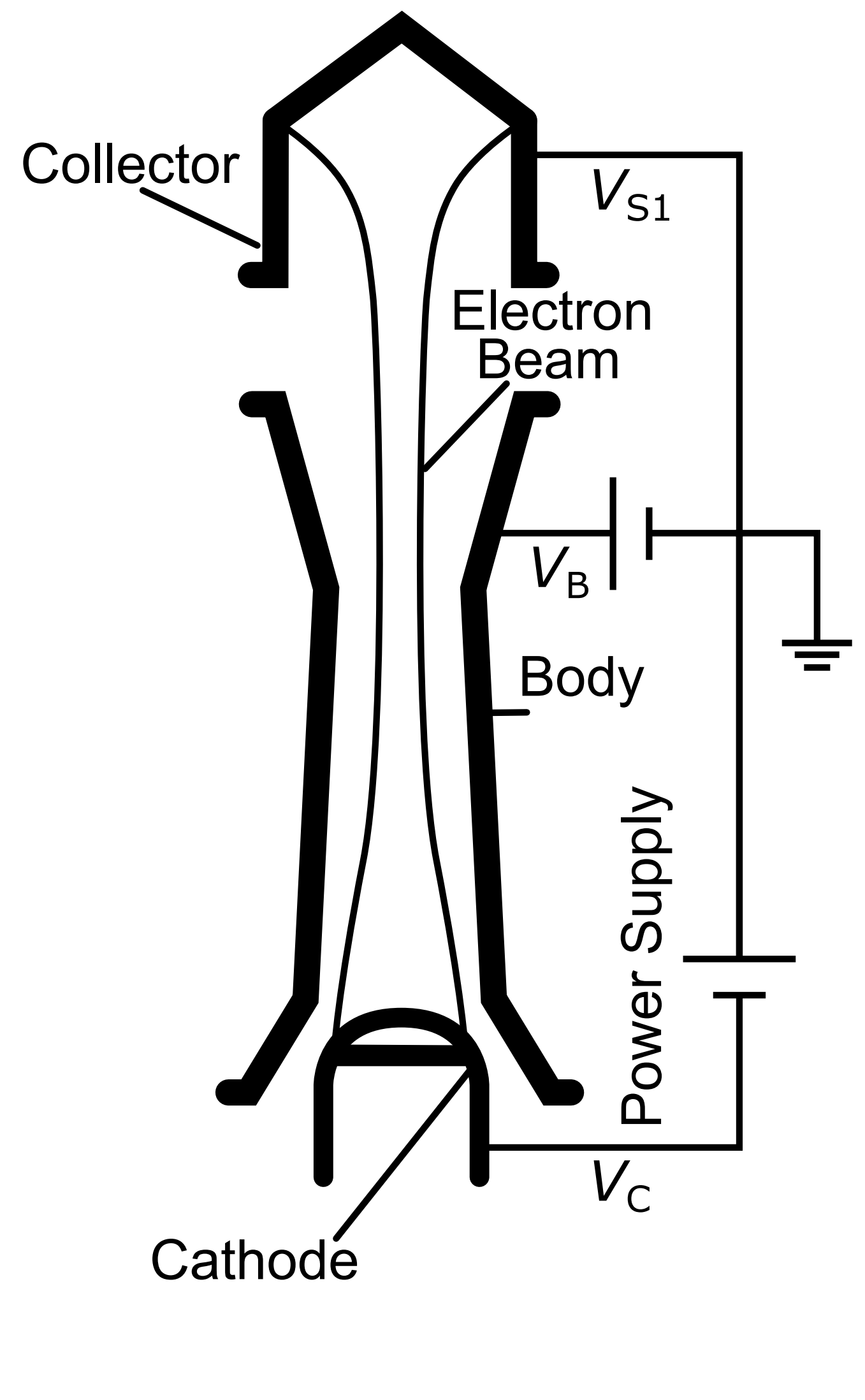




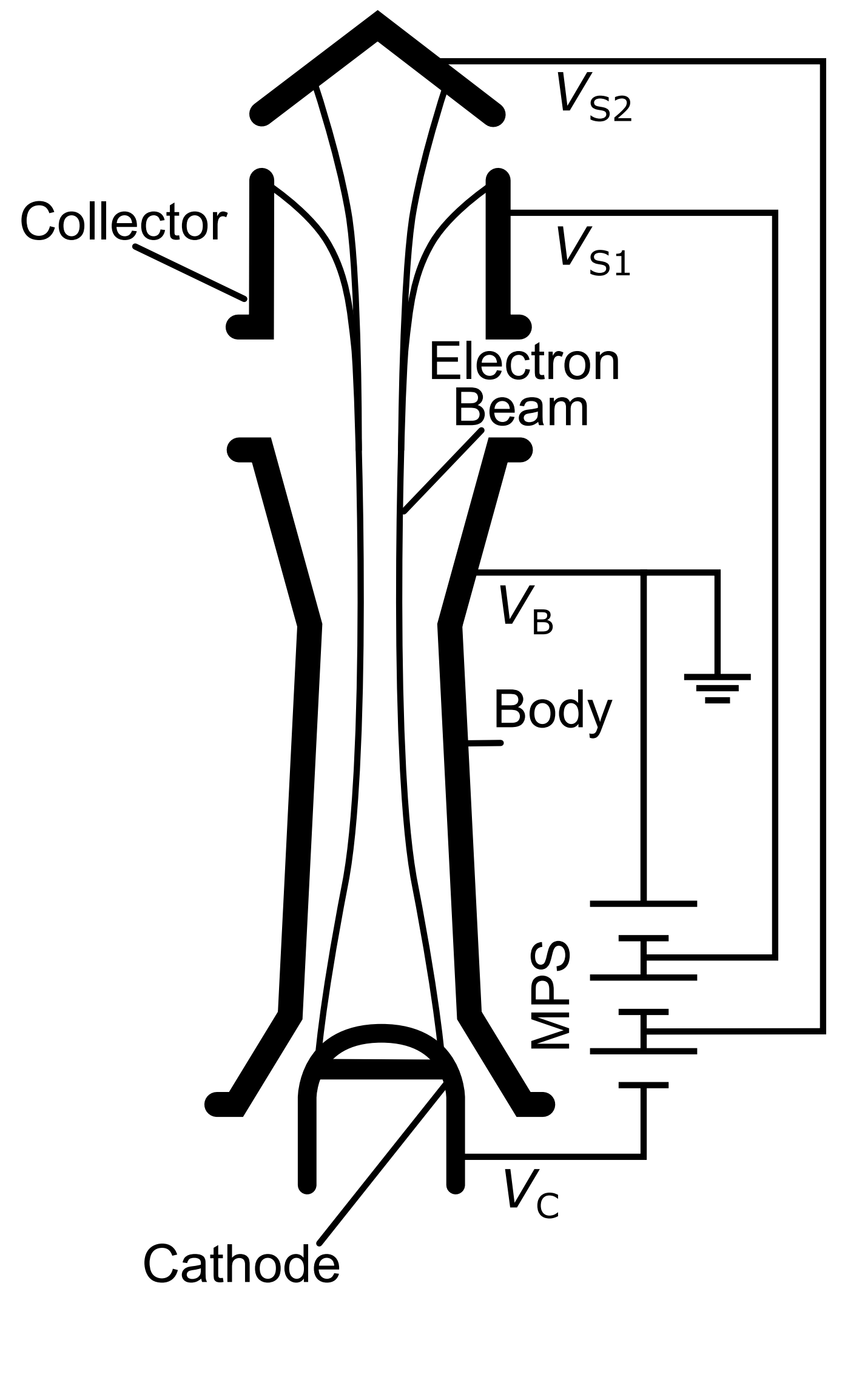




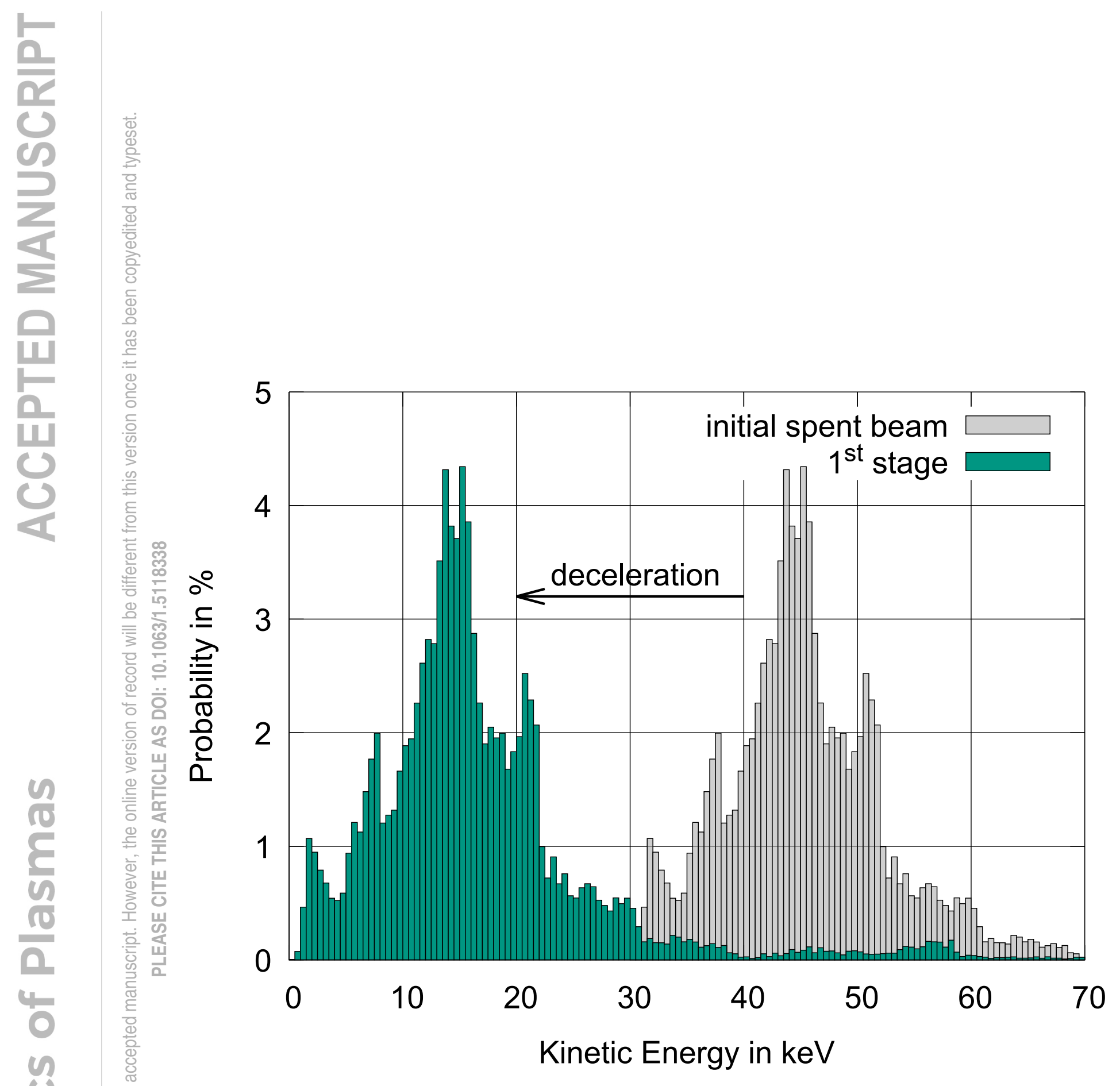




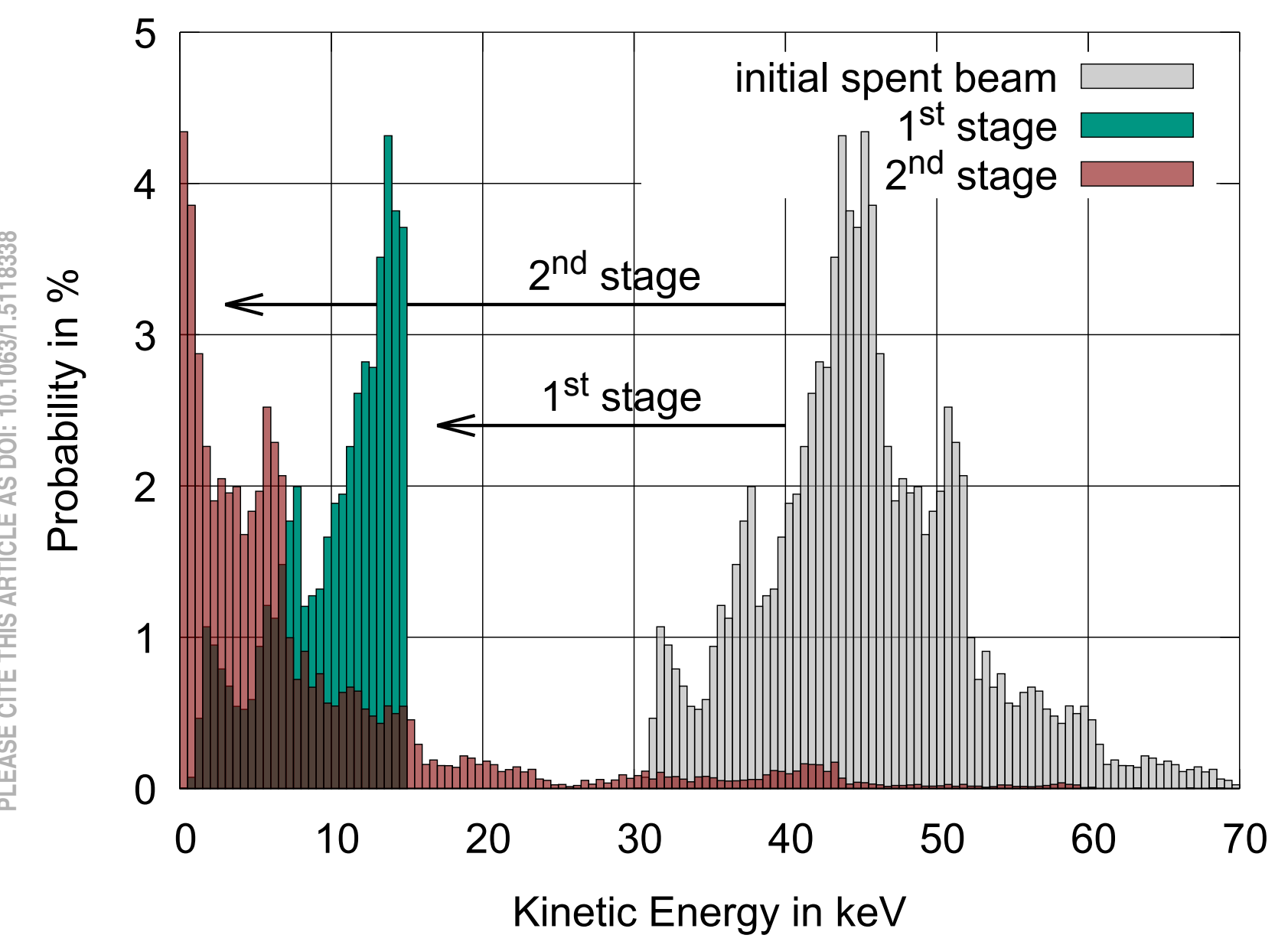



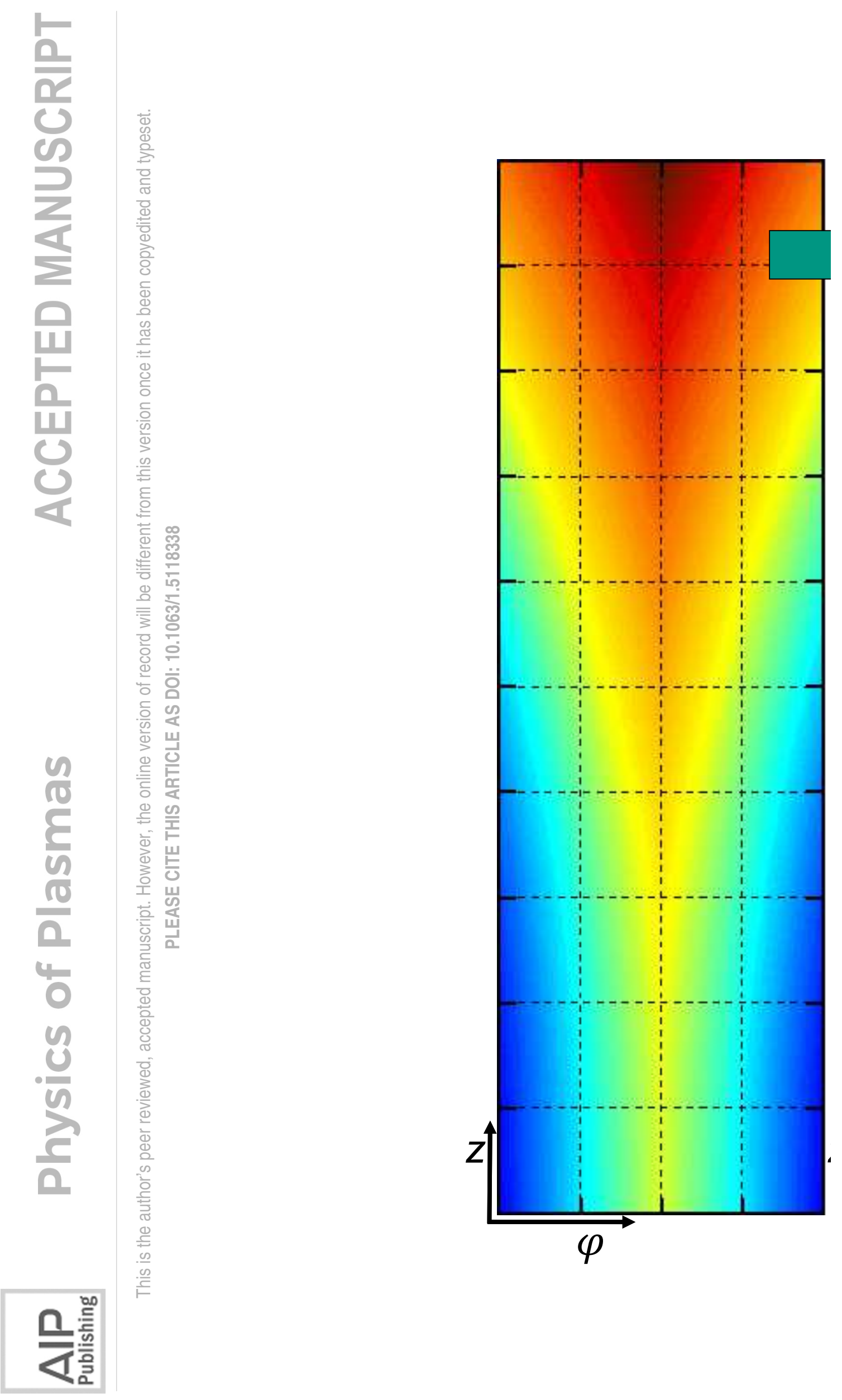

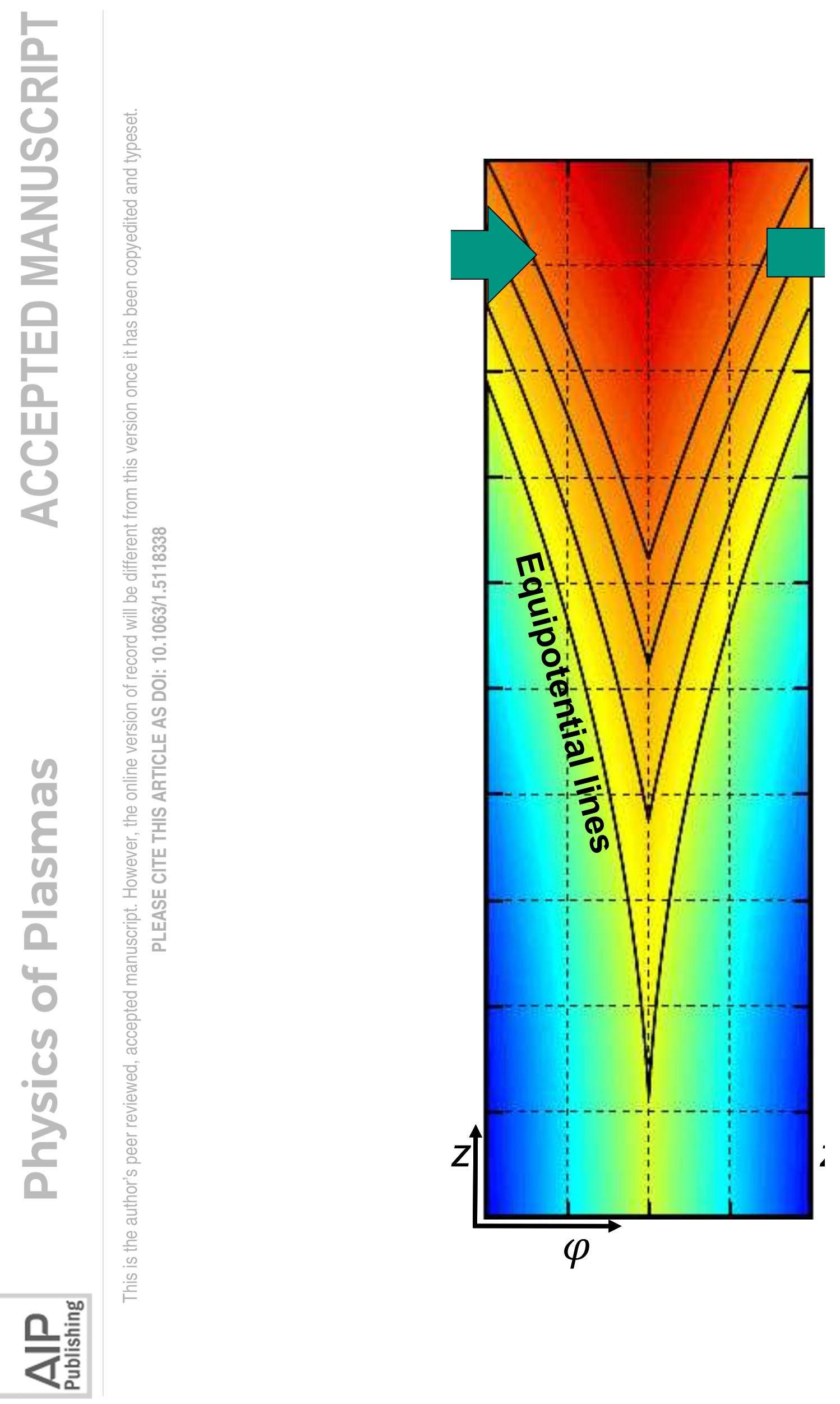


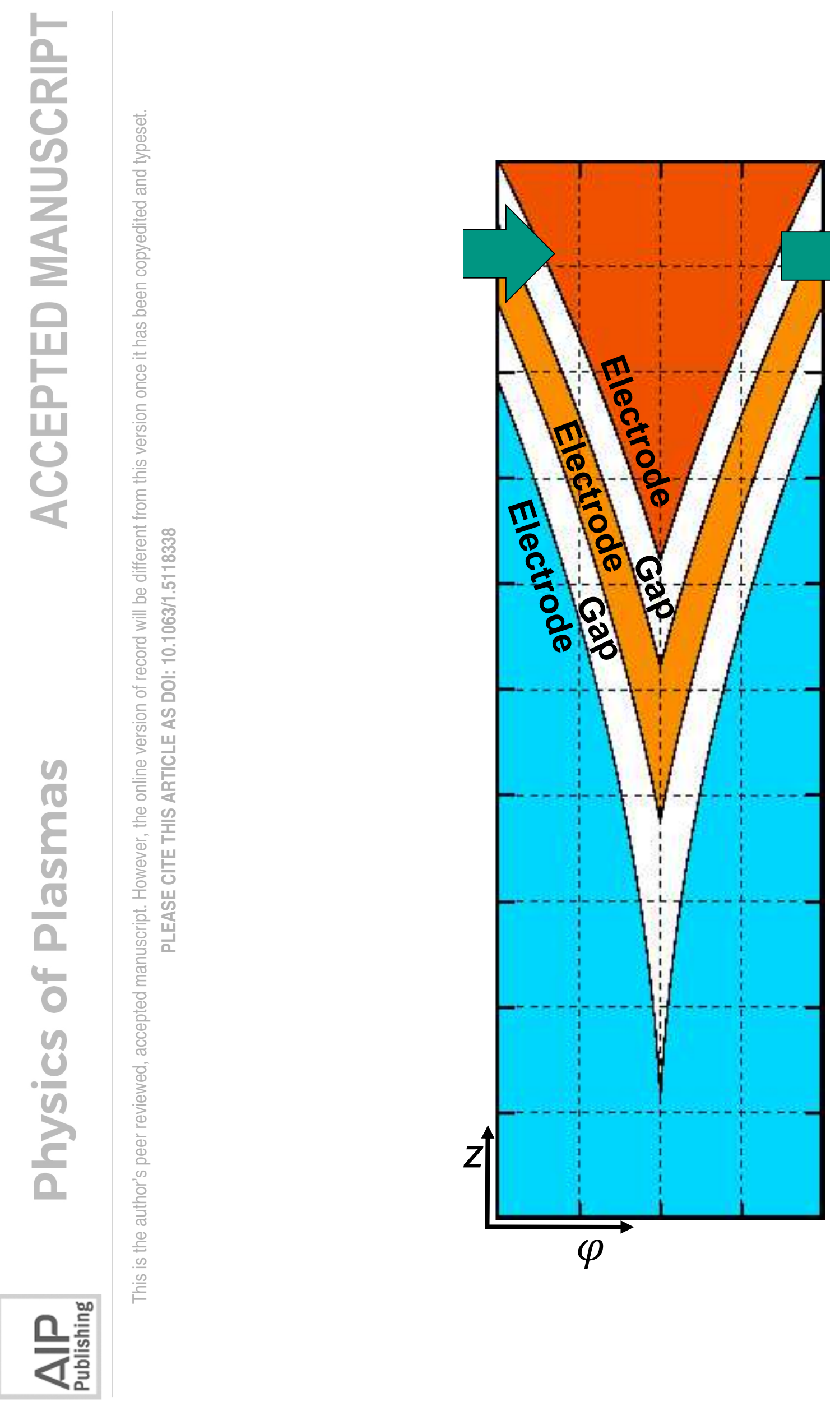



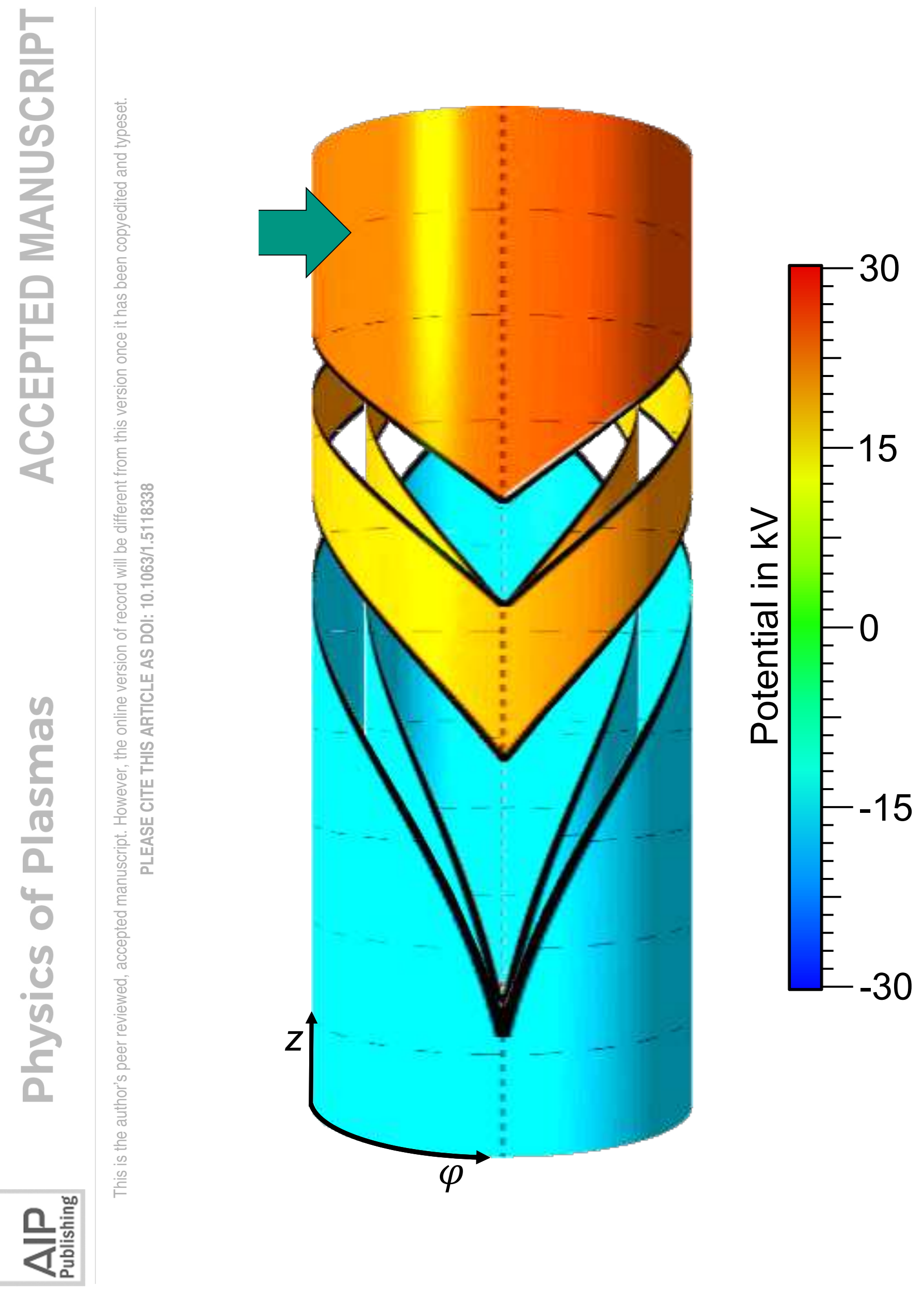


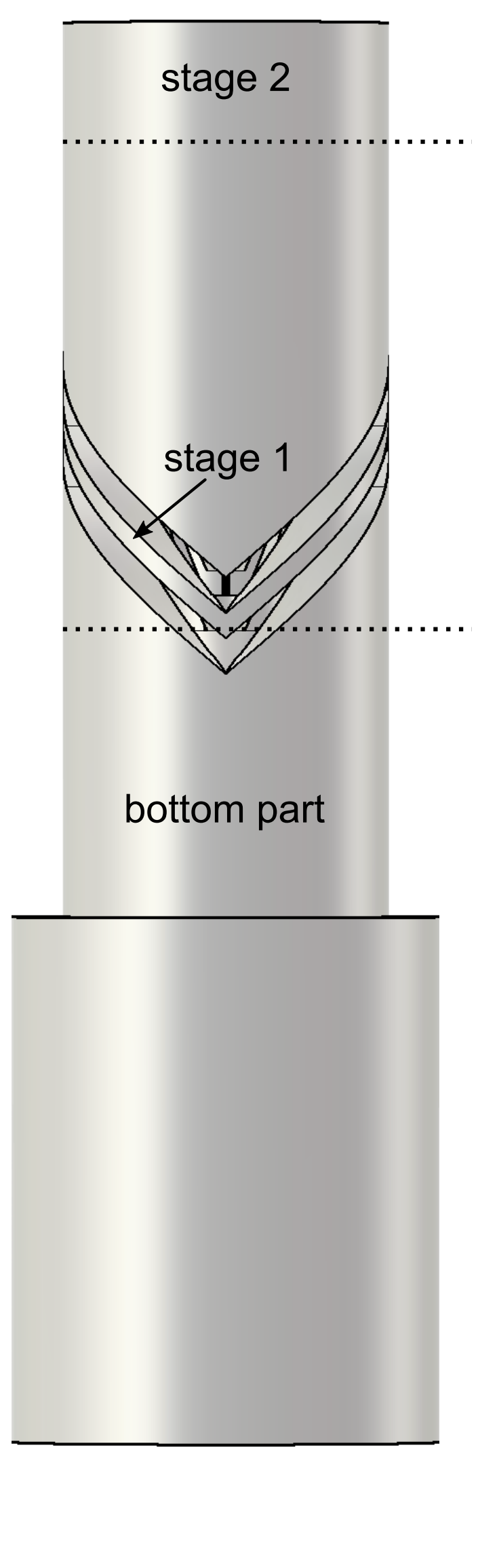




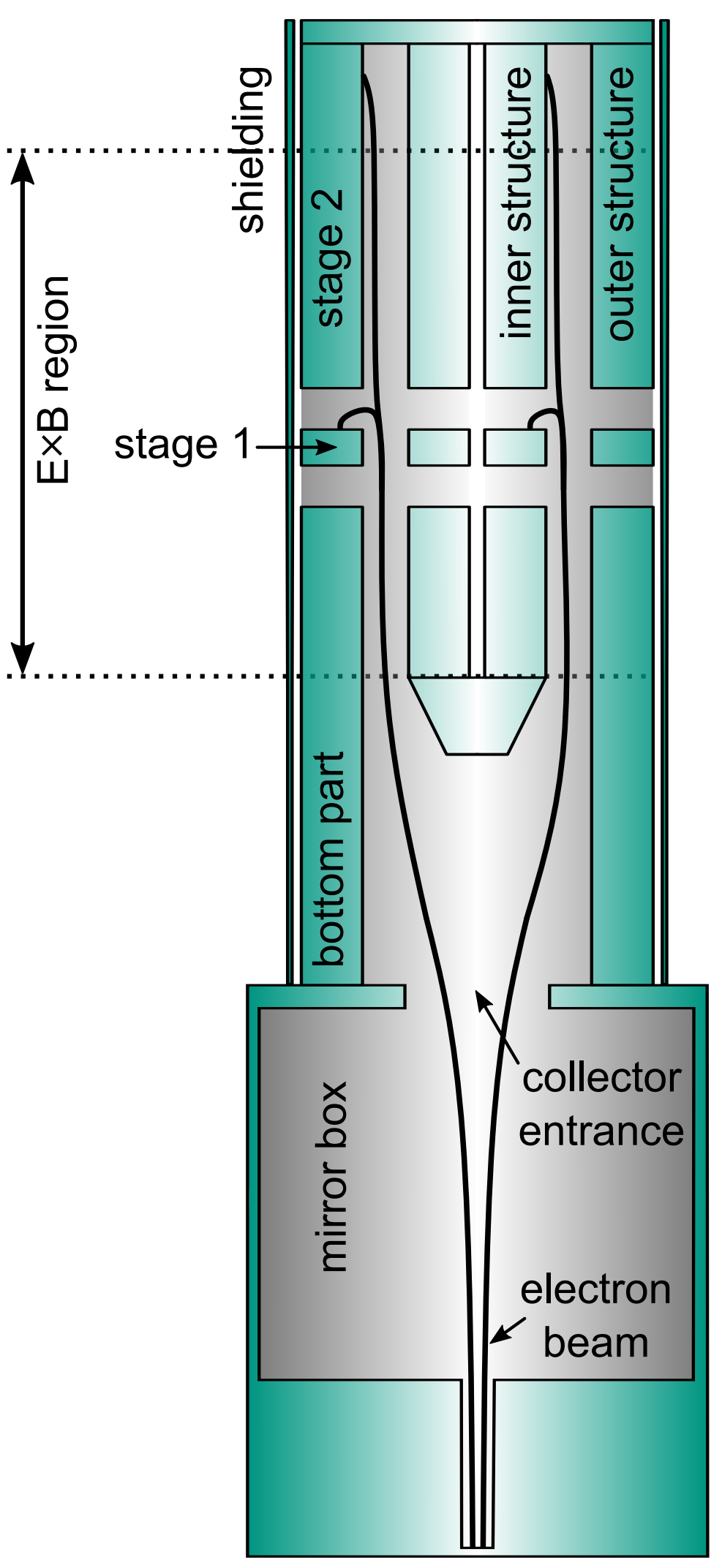

兄耪言 


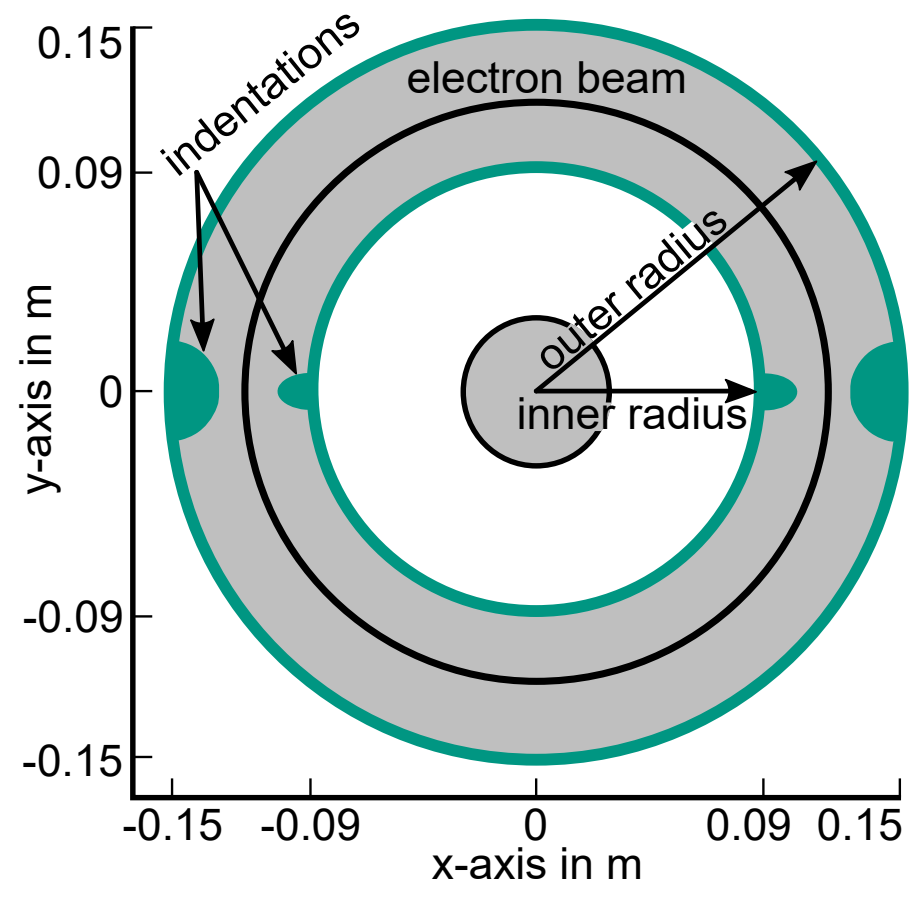

兄喜譬 


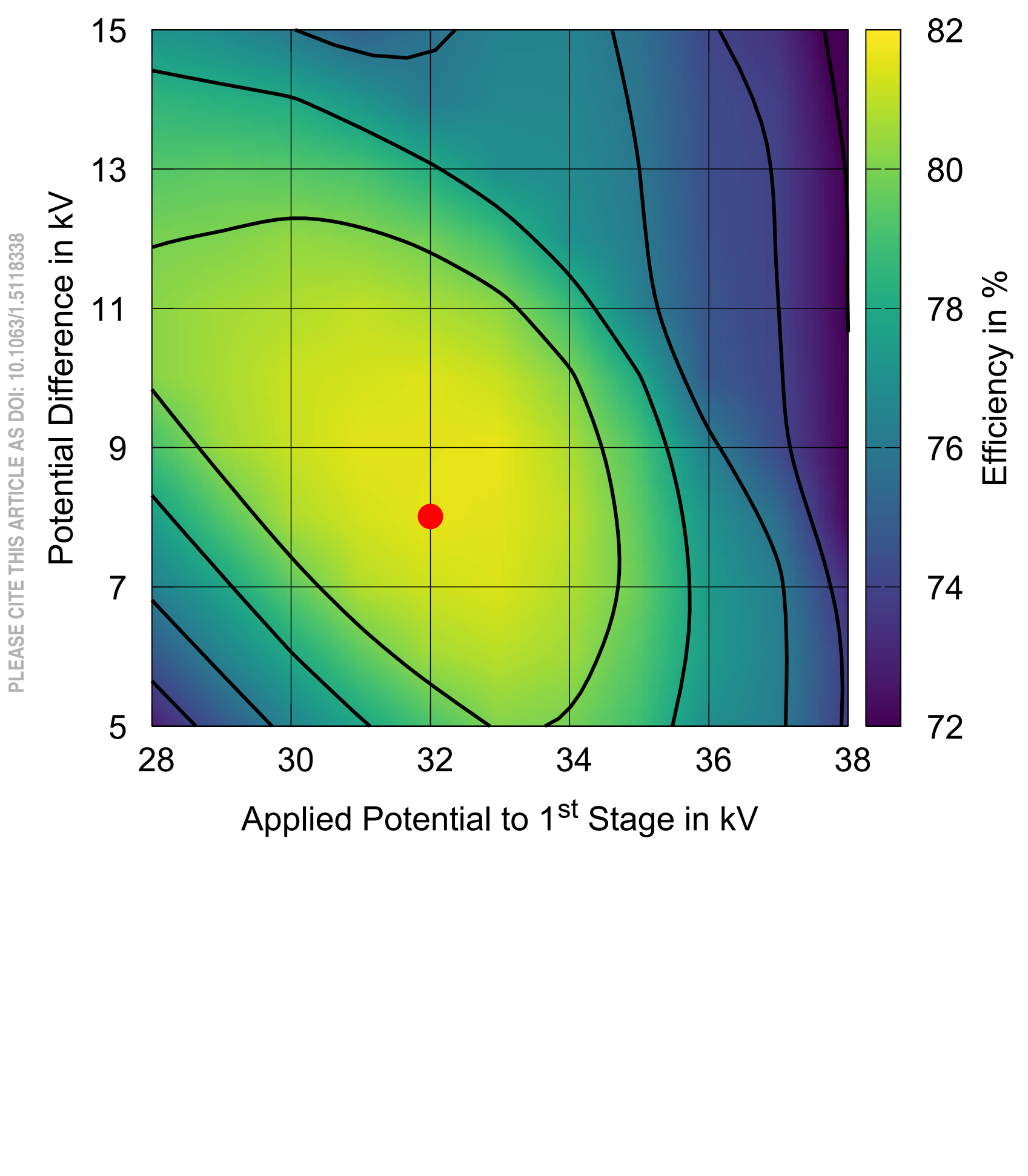




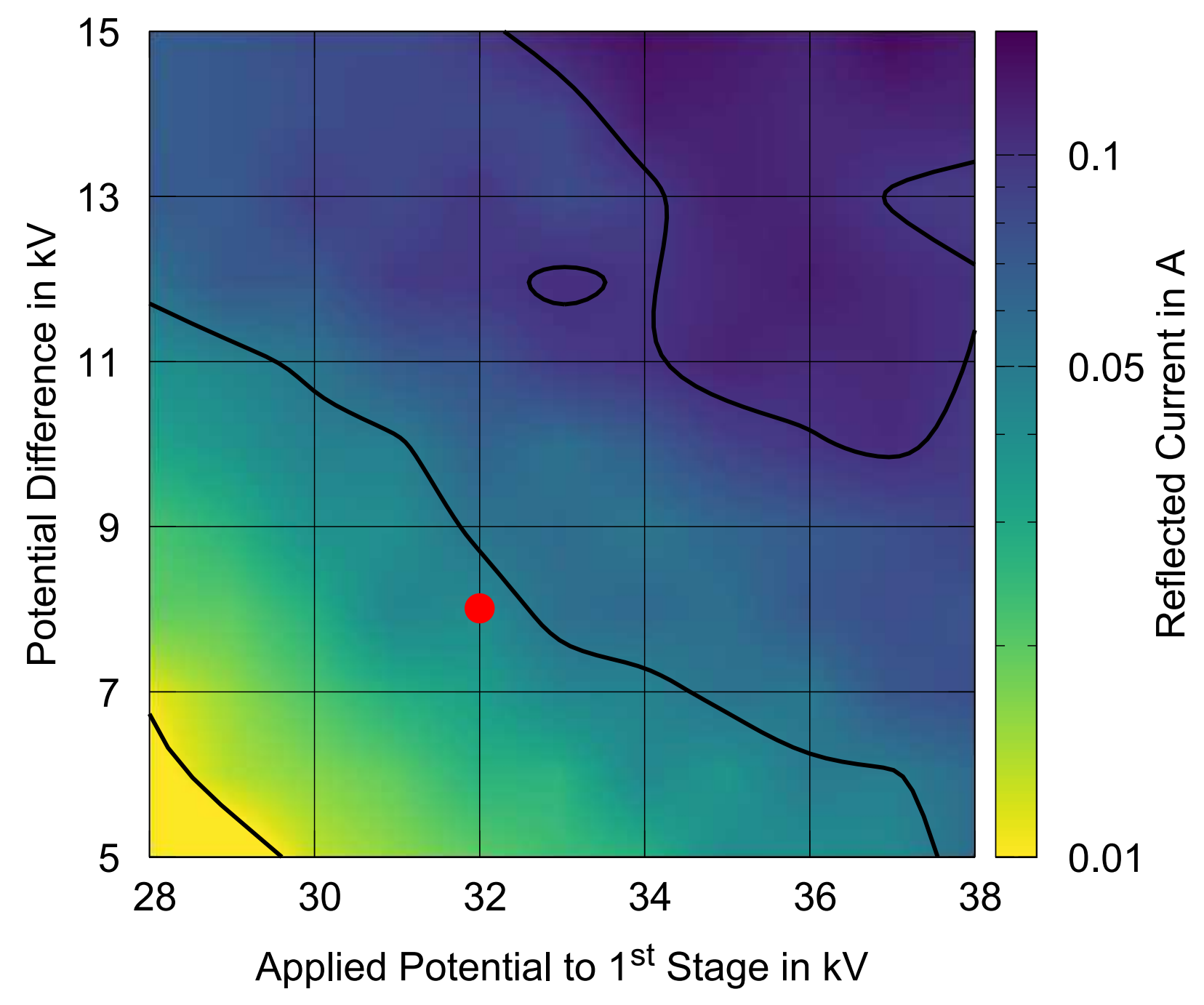




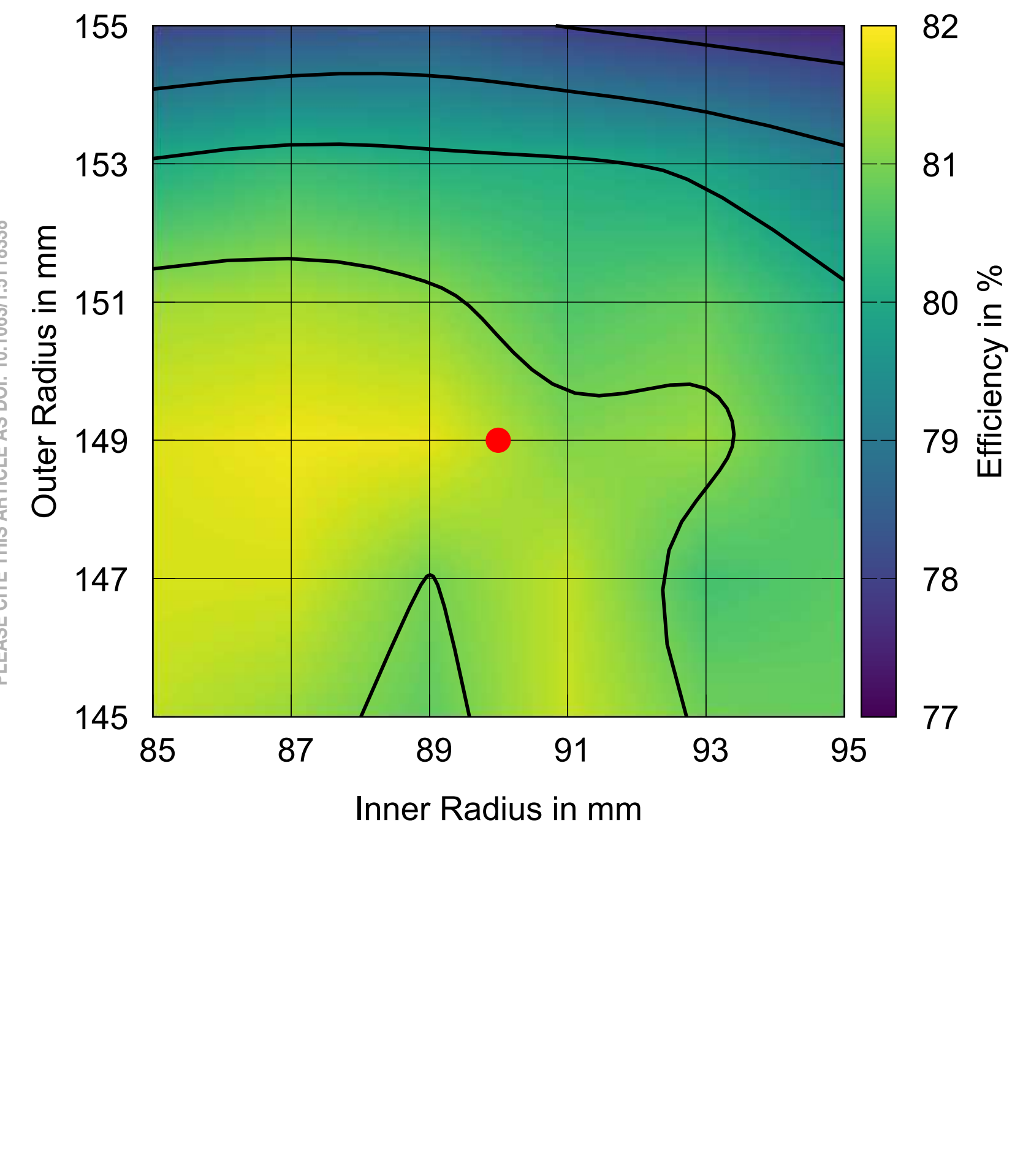




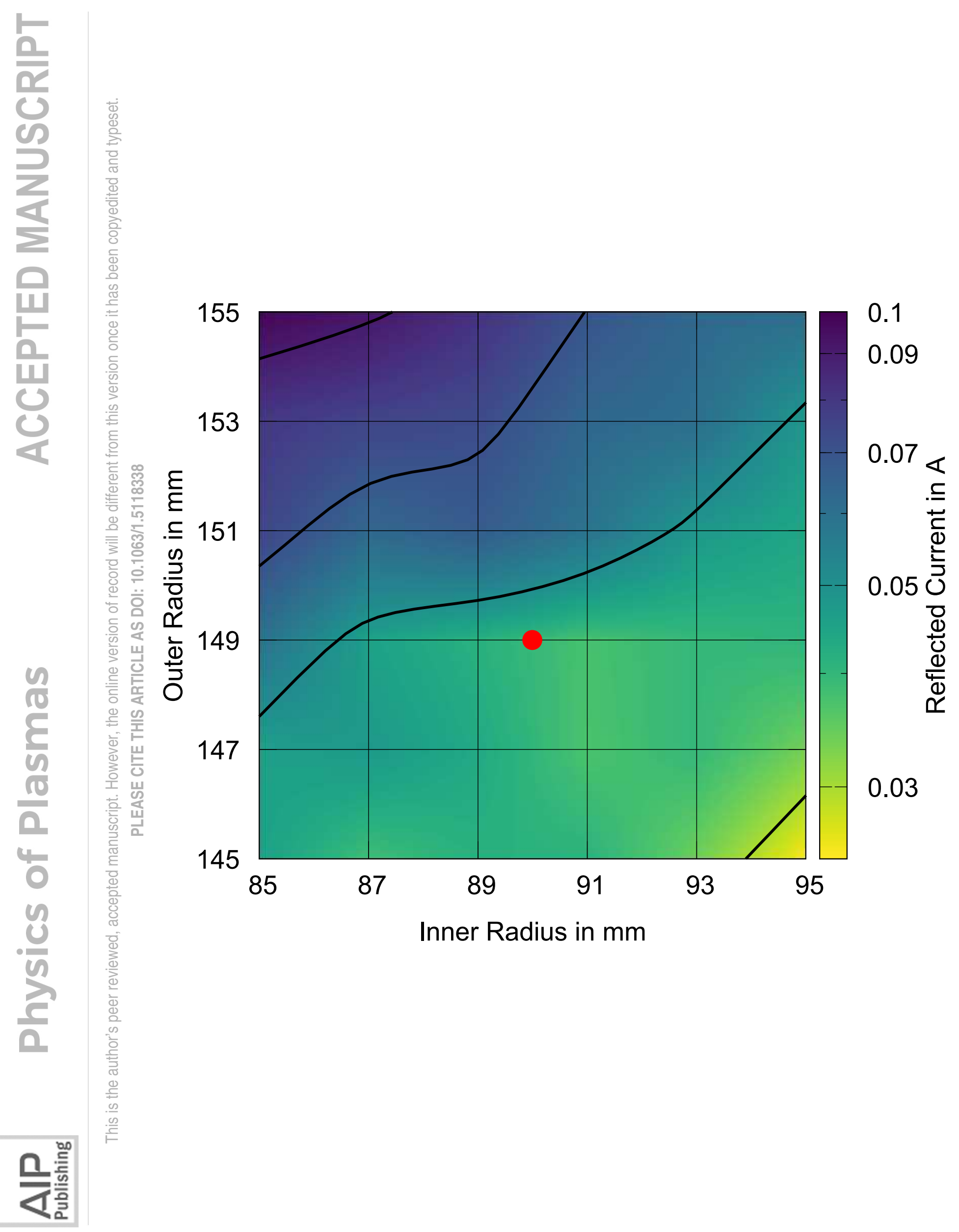




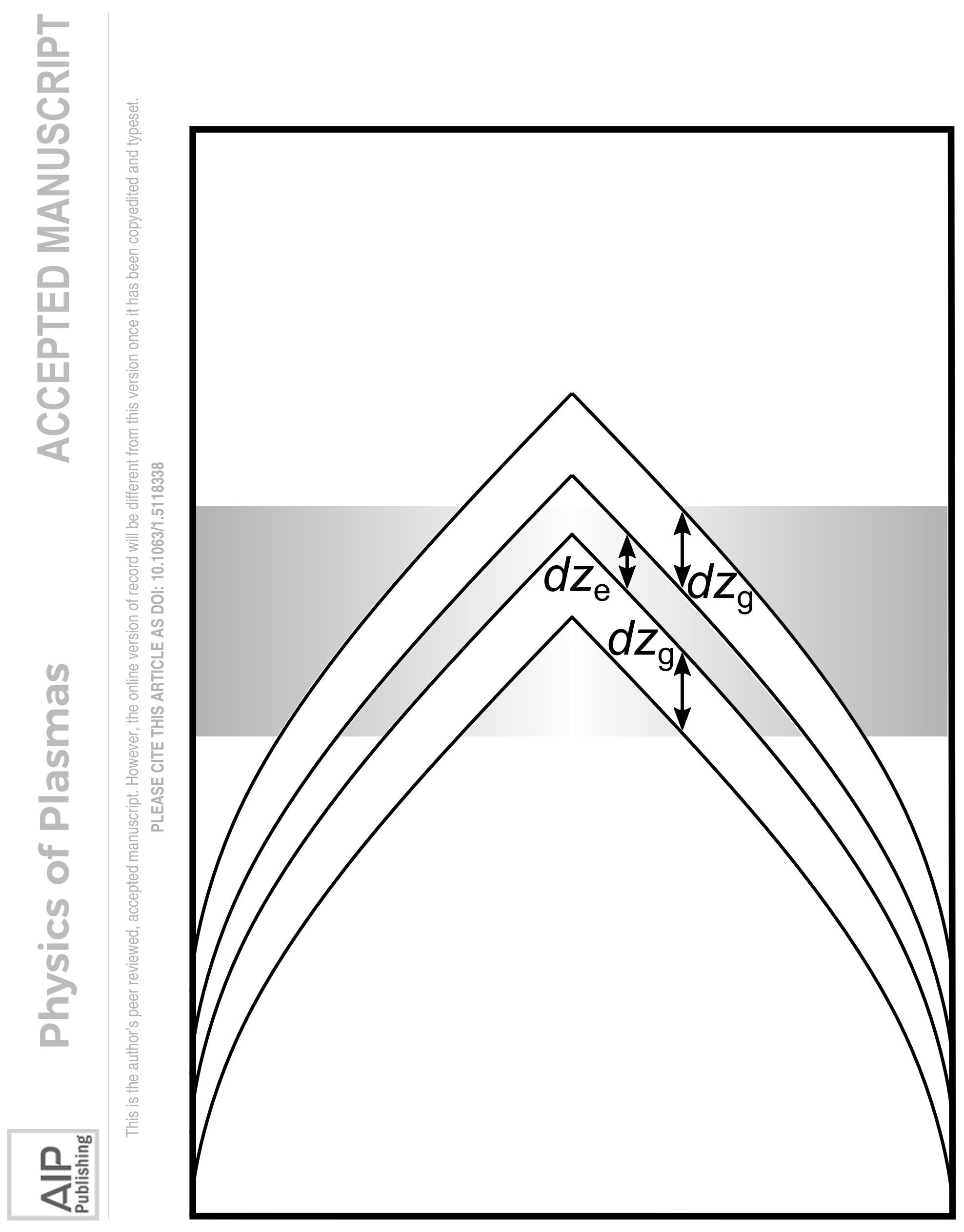




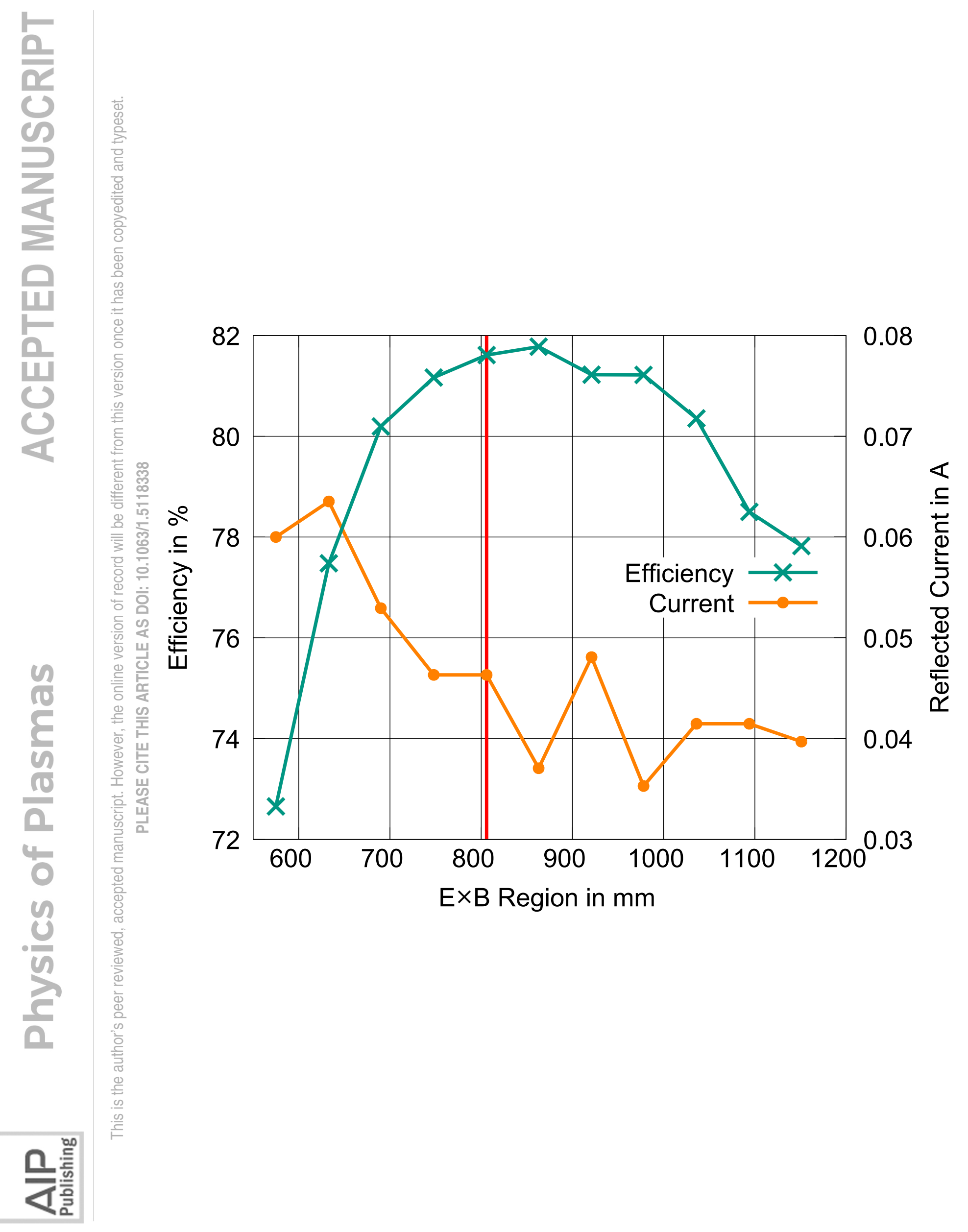



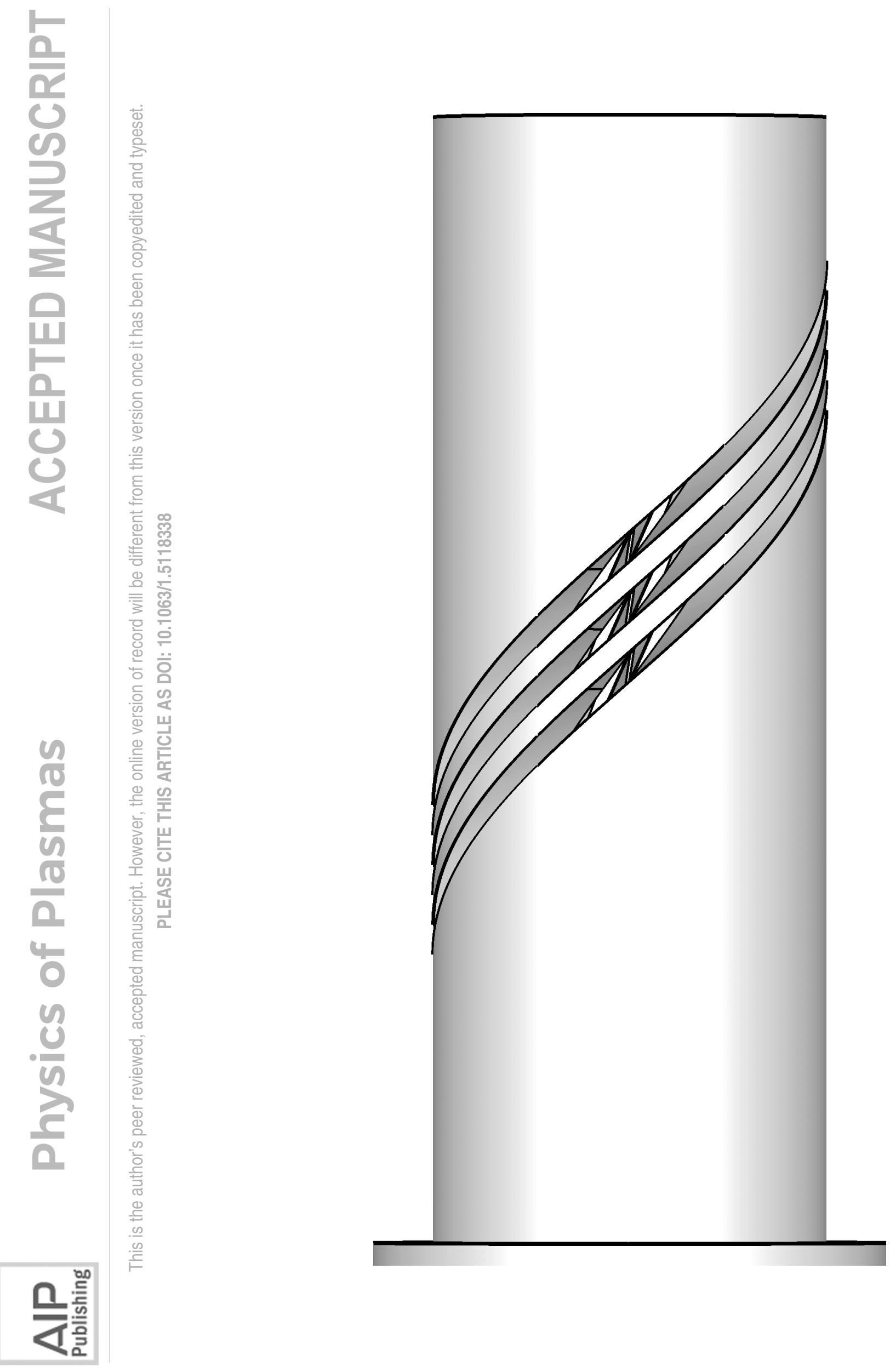

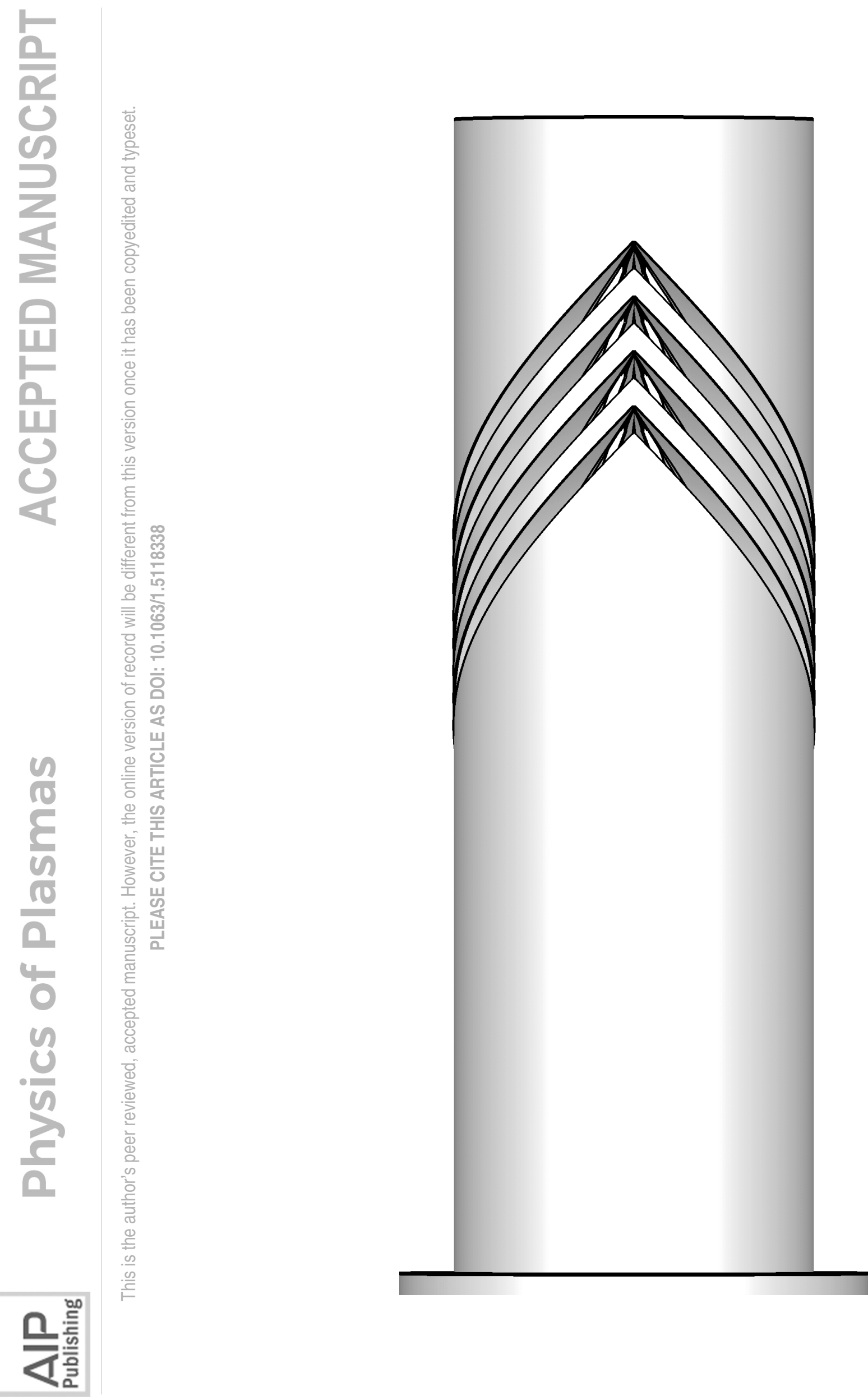


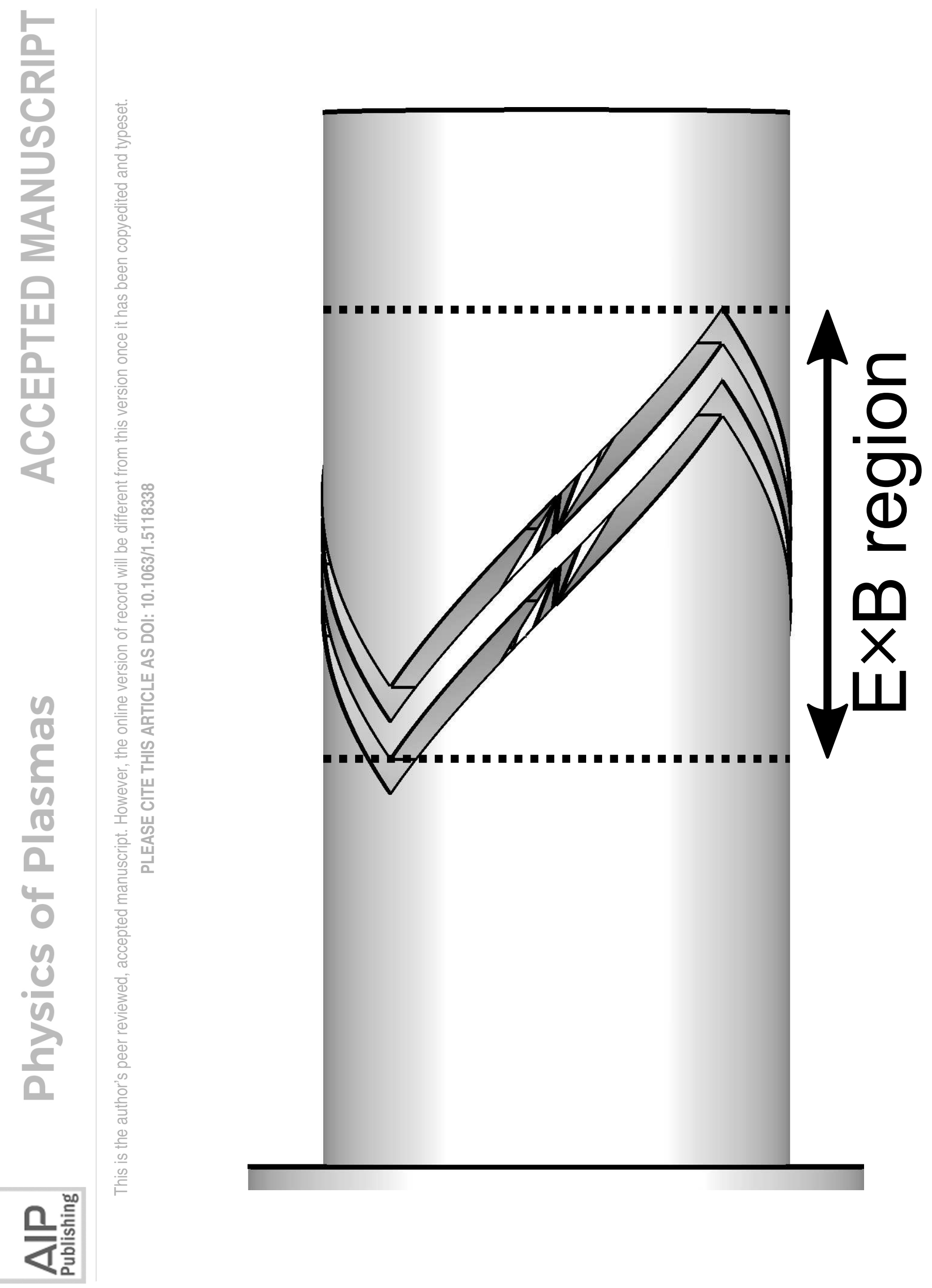




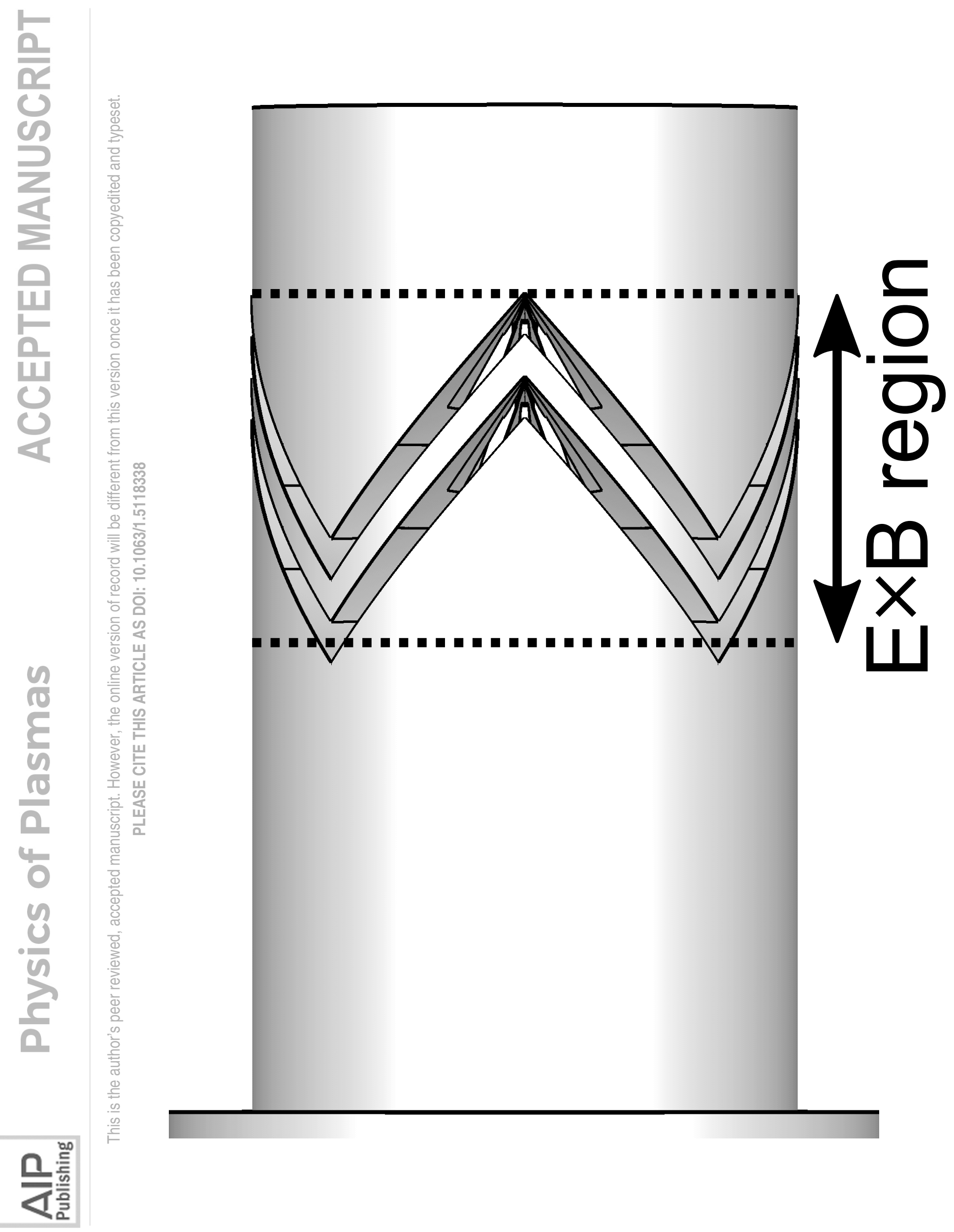




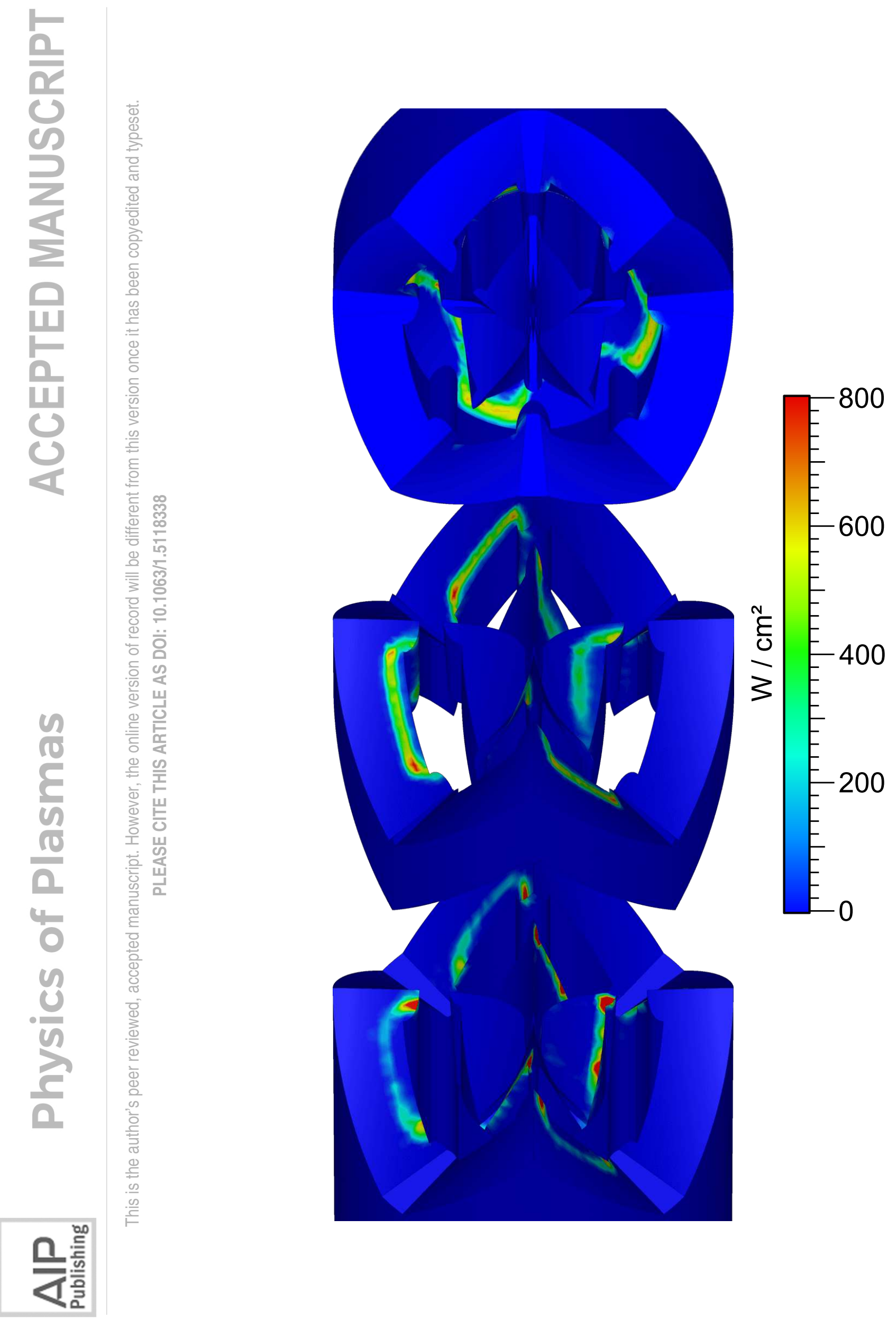



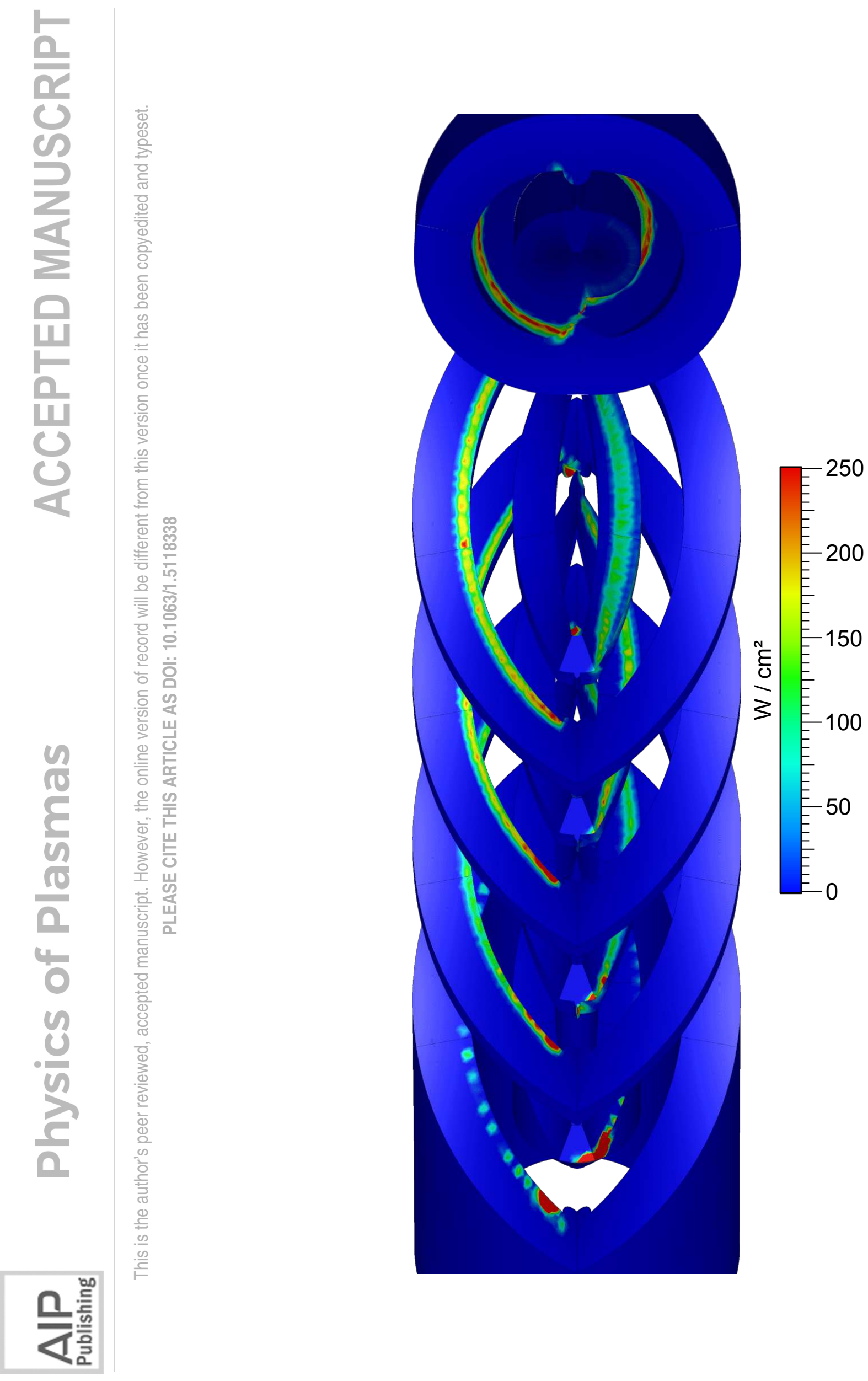